IZA DP No. 5424

Dynamic Evaluation of Job Search Assistance

Stephen Kastoryano

Bas van der Klaauw

January 2011

Forschungsinstitut zur Zukunft der Arbeit Institute for the Study of Labor 


\title{
Dynamic Evaluation of Job Search Assistance
}

\author{
Stephen Kastoryano \\ University of Amsterdam, \\ VU University Amsterdam and Tinbergen Institute \\ Bas van der Klaauw \\ VU University Amsterdam, \\ Tinbergen Institute and IZA
}

\section{Discussion Paper No. 5424 \\ January 2011}

\author{
IZA \\ P.O. Box 7240 \\ 53072 Bonn \\ Germany \\ Phone: +49-228-3894-0 \\ Fax: +49-228-3894-180 \\ E-mail: iza@iza.org
}

\begin{abstract}
Any opinions expressed here are those of the author(s) and not those of IZA. Research published in this series may include views on policy, but the institute itself takes no institutional policy positions.

The Institute for the Study of Labor (IZA) in Bonn is a local and virtual international research center and a place of communication between science, politics and business. IZA is an independent nonprofit organization supported by Deutsche Post Foundation. The center is associated with the University of Bonn and offers a stimulating research environment through its international network, workshops and conferences, data service, project support, research visits and doctoral program. IZA engages in (i) original and internationally competitive research in all fields of labor economics, (ii) development of policy concepts, and (iii) dissemination of research results and concepts to the interested public.
\end{abstract}

IZA Discussion Papers often represent preliminary work and are circulated to encourage discussion. Citation of such a paper should account for its provisional character. A revised version may be available directly from the author. 
IZA Discussion Paper No. 5424

January 2011

\section{ABSTRACT}

\section{Dynamic Evaluation of Job Search Assistance*}

This paper evaluates a job search assistance program for unemployment insurance recipients. The assignment to the program is dynamic. We provide a discussion on dynamic treatment effects and identification conditions. In the empirical analyses we use administrative data from a unique institutional environment. This allows us to compare different microeconometric evaluation estimators. All estimators find that the job search assistance program reduces the exit to work, in particular when provided early during the spell of unemployment. Furthermore, continuous-time (timing-of-events and regression discontinuity) methods are more robust than discrete-time (propensity score and regression discontinuity) methods.

JEL Classification: $\quad$ C22, J64, J68

Keywords: treatment evaluation, dynamic enrollment, empirical evaluation

Corresponding author:

Bas van der Klaauw

Department of Economics

VU University Amsterdam

De Boelelaan 1105

NL-1081 HV Amsterdam

The Netherlands

E-mail: bklaauw@feweb.vu.nl

\footnotetext{
* Thanks to Pierre Koning and seminar participants at the University of Tilburg, University of Zurich, Bristol University, Netherlands Bureau of Economic Policy Analyses, University of Essex, EALE/SOLEmeeting in London, the ESWM in Shanghai, and the IZA/IFAU conference on Labor Market Policy Evaluation 2010 for useful comments.
} 


\section{Introduction}

Since the 1990s, many countries offer job search assistance to stimulate the exit to work of unemployed workers. Policymakers often consider this to be a necessary requirement in a system with relatively generous benefits. In their recent survey, Card, Kluve and Weber (2010) stress that job search assistance programs often have relatively good short-run effects. Also in the Netherlands job search assistance is offered frequently. In fact, the Netherlands is one of four OECD countries spending more than one percent of GDP on active labor market programs (see OECD, 2010). However, empirical evidence on the effectiveness of Dutch active labor market programs is very limited, which is particularly true for job search assistance programs. In this paper, we focus on job search assistance for unemployed workers in the Dutch primary education sector. As outcome variable we consider the exit from unemployment, which is also the key variable of interest to policymakers. Focussing, for example, on wages is less interesting since a majority of the unemployed teachers return to a job in the primary school sector where wages are determined by collective bargaining and are almost a deterministic function of the individual's age (with some extras for managerial responsibilities).

In the Netherlands, the use of randomized social experiments in social insurance schemes is uncommon. Van den Berg and Van der Klaauw (2006) describe the most recent experiment conducted in 1998/99. In our paper, we deal with nonexperimental data, which makes the empirical evaluation non-trivial. First, the evaluation of job search assistance suffers from the usual selection problem that participation might be related to (unobserved) individual characteristics. Second, job search assistance often does not start immediately after an individual enters unemployment, and the start of the program differs between individuals. When staying unemployed sufficiently long, all individuals will eventually enter job search assistance, which complicates the evaluation (see Abbring and Heckman, 2007; for a survey on dynamic treatment evaluation). Some individuals have already left unemployment at the moment they should enter job search assistance. Dynamic selection complicates the construction of a comparable control group.

Even though we only evaluate a single treatment, the effects can differ between individuals. Not only because individuals are heterogeneous, but also because the impact of the program can depend on the moment of starting job search assistance. For example, lock-in effects may be more substantial for unemployed workers with relatively favorable labor market prospects (or those who are still relatively shortterm unemployed). We investigate to what extent the timing of entering job search assistance affects its effectiveness. Obviously, this is informative about the targeting efficiency of the program and such knowledge may improve the profiling of unem- 
ployed workers. In the current policy debate this issue becomes more important. In the next few years the Dutch government is facing substantial budget cuts, which will affect the expenditures on active labor market programs.

In our empirical analyses, we use administrative data from a unique institutional environment in which the assignment to job search assistance is very clearly described, and allows for different evaluation methods. The participation in job search assistance depends only on a limited set of observable characteristics, and there are some clear discontinuities. We exploit this when estimating the effect of job search assistance using propensity score matching and regression discontinuity estimators. We compare the results of these estimators to assessing the program's effectiveness using the timing-of-events estimator. Because the institutional environment guarantees that the underlying assumptions of the different estimators are satisfied, we obtain valuable insights in the performance (in a real life setting) of some of the most popular cross-sectional estimators for policy evaluation used in recent microeconometric research.

In the US, interventions during unemployment often start at a fixed moment, e.g. Black, Smith, Berger and Noel (2003) study training services starting after two weeks of unemployment. A substantial share of the econometric methodology, therefore, focuses on static treatment evaluation (e.g. Imbens and Wooldridge, 2009; for a recent survey). However, in many European countries the timing of entry into labor market programs often varies between individuals. Other than in the Netherlands, this is, for example, the case in Sweden (e.g. Fredriksson and Johansson, 2008; and Sianesi, 2004), Switzerland (e.g. Gerfin and Lechner, 2002; and Lalive, Van Ours and Zweimüller, 2008), France (Crépon, Ferracci, Jolivet and Van den Berg, 2010), and Germany (Lechner and Wunsch, 2009). A relatively large literature attempts to fit such a dynamic setting into the standard potential outcome model (e.g. Gerfin and Lechner, 2002; and Sianesi, 2004). Sianesi (2004) discusses the complications of finding a suitable control group in case all individuals will eventually enter a program. Considering those individuals who are observed not to have received treatment implies conditioning on future outcomes. Fredriksson and Johansson (2008) argue that not accounting for dynamic selection may bias treatment evaluation estimators.

This paper fits within the recently growing literature on dynamic treatment evaluation, surveyed by Abbring and Heckman (2007). The contribution is not only empirical, but by comparing different methods we also intend to make some methodological contributions. We discuss the implementation of various estimators in a dynamic setting, and show that all dynamic evaluation methods rely on assuming that individuals do not anticipate the exact start of treatment. Empirical studies using the timing-of-events methodology often explicitly justify this assumption (e.g. 
Van den Berg, Van der Klaauw and Van Ours, 2004), but this is ignored in studies using other evaluation estimators. Propensity score matching methods mainly focus on the conditional independence assumption, which is often justified from the richness of the data. Gerfin and Lechner (2002) and Sianesi (2004), for example, argue that information on past labor market outcomes and subjective assessments of labor market prospects justify the conditional independence assumption. Lalive, Van Ours and Zweimüller (2008) show that even if such information is available, applying timing-of-events estimation and propensity score matching estimation give substantially different results. Unlike our institutional setting, in their setting it is unclear whether the conditional independence assumption is valid. Additionally, we apply regression-discontinuity estimation. The implementation of regression-discontinuity estimation in a dynamic setting is non-standard mainly because forward-looking individuals might take into account the timing of entering the program when deciding about their job search strategy (e.g. Rosenzweig and Wolpin, 2000). We follow Abbring and Van den Berg (2005) when applying regression-discontinuity estimation. As far as we know this paper is the first using the regression-discontinuity estimator for duration models in an empirical application.

In the empirical application we mainly focus on the ex-post effects of job search assistance, which are the causal effects of actually entering the program. Using the content and the goal of the program we try to decompose this ex-post effect into a lock-in effect and an improvement in job search. In particular, we exploit that job search assistance is most intensive during the first eight weeks. Most treatment evaluation estimators are not informative on ex-ante effects, which are the effects of being enrolled in a benefits scheme which includes an active labor market program compared to a scheme without this particular program. When applying regressiondiscontinuity we compare individuals who should enter the program quickly after becoming unemployed with those who enter later during the spell of unemployment. By comparing reemployment rates between both groups before actually entering the program, we can get some idea about the threat effect of the program which provides some insight in the size of possible ex-ante effects.

The paper is organized as follows. In Section 2 we provide details about the relevant unemployment insurance scheme, and the job search assistance program. Section 3 presents the data. In Section 4 we provide a general framework for dynamic treatment evaluation. We discuss timing-of-events estimation in Section 5. Section 6 deals with propensity score methods, and Section 7 presents the results from regression discontinuity estimation. In section 8 we compare the results from the different methods. Finally, Section 9 concludes. 


\section{Institutional setting}

\subsection{Unemployment insurance for the primary education sec- tor}

Our data concern former employees of Dutch primary education institutions who are entitled to collecting unemployment insurance benefits. Primary education institutions, like all public sector institutions, must bear their own unemployment insurance risk. However, because primary education institutions are relatively small, they were forced in 1996 to participate in a sector fund, called the Participation Fund. This fund is responsible for collecting premiums, and paying unemployment insurance benefits.

Unemployed workers from the primary education sector have the same entitlement rules and obligations as unemployed workers from the private sector. Their benefits are, however, more generous both in terms of level and entitlement period. All individuals below age 65 who worked at least 26 weeks of the 36 weeks prior to becoming unemployed are entitled to collecting unemployment insurance benefits. Furthermore, a worker should have lost at least five working hours per week or more than $50 \%$ of their weekly working hours (if less than 10). Finally, the job loss should not be voluntary, and the individual should not be held responsible for the job loss.

Each unemployed worker receives unemployment insurance benefits for at least three months. If an unemployed worker worked at least 52 days during four out of the past five calendar years ('year'-condition), the entitlement period is extended to six months. For each additional year of employment (so beyond four years) the entitlement period for unemployment insurance benefits is extended by one month. For an entitlement period of one year, the unemployed worker must have worked for at least ten years. For the maximum entitlement period of 38 months, 36 years of work is required. During the first year, the benefits level is $78 \%$ of the last wage (capped at 167.70 euro per day). After that, the benefits level decreases to $70 \%$ of this last wage.

After the usual benefits entitlement period ends, an individual may be entitled to extended benefits at $70 \%$ of the last wage. The duration of the extended benefits depends on age and work experience. Individuals below age 40 and those with less than five years of work experience do not receive extended benefits. A 40-year old individual with five years of work experience receives one additional year of benefits, while a 51-year old with more than ten years of work experience receives extended benefits until reaching the retirement age of 65 .

Benefit recipients have the obligation to actively search for work, and to accept suitable job offers. Furthermore, they should provide all necessary information to 
the Participation Fund, and keep them informed about possible changes in their situation (e.g. vacation, sickness, pregnancy, etc.). If the individuals fails to comply to these rules, a sanction can be applied which leads to a temporary reduction of the benefits level.

Over the last few years, the unemployment rate in the primary education sector was about $2 \%$ compared to $4 \%$ in the private sector. The main reason for the lower unemployment rate is a much lower inflow. The outflow from unemployment in the primary education sector is comparable to that of the private sector. There are compositional differences between unemployed workers in the primary education sector and the private sector. About $80 \%$ of the workers in primary education are women, and the average age is somewhat higher than in the private sector.

\subsection{The job search assistance program}

Since July 2005, institutions in the public sector are also responsible for reintegrating their former employees. This implies that the Participation Fund became responsible for financing and organizing active labor market programs. These activities fall into two categories. First, a regular program in which the majority of the benefit recipients participate. This program focusses on job applications, but can also include some vocational training. Second, a short job search assistance program focussing on networking skills in addition to job application training. Unemployed workers under age 60 are obliged to participate in these programs if these are offered to them. Individuals who refuse to participate will be sanctioned with a substantial reduction of their benefits. Participation in a program does not affect the entitlement to benefits, i.e. the benefit entitlement period is not extended and individuals do not get additional benefits while being in the job search assistance program. Most individuals aim at finding new work again in the primary education sector, but about one-third of the observed exits are towards employment outside this sector.

The program is only provided to individuals who receive benefits for at least eight hours per week, and with an entitlement period exceeding three month. Individuals with less than 13 months entitlement at the moment of entering the program are assigned to the short program. Individuals with a longer entitlement period enter the regular program. The timing of assignment to the program differs depending on an age criteria. Individuals above age 50 (at the first day of unemployment) and (low-skilled) individuals who were previously employed in a subsidized job, should enter the job search assistance program immediately after starting collecting benefits. Individuals under age 50 and who are not low-skilled, enter the program only after six months of unemployment. 
Only $8 \%$ of all job search assistance programs offered are short programs. These services last three months and focus on presentation, writing a vitae and application letter, networking and efficient job search. The remaining $92 \%$ of the job search assistance programs offered are regular programs. In the empirical analyses we will not distinguish between both programs. The programs are offered at 11 locations providing all the same program. Once invited the benefit recipients can choose the location but $75 \%$ of the individuals accept the default. The remaining $25 \%$ almost always opt for the location nearest to their home.

The regular program starts with an intake interview to determine the required activities. These range from improving language skills, providing psychological support, providing short vocational class, and offering the type of job search assistance services also included in the short program. The training takes place both in individual and group meetings. The intensity of the meetings depends upon the needs of the individual. The first weeks are often more intense, with two to three meetings per week with training officers. The total time spend in these meetings is about one full working day per week. After this period, the participants usually visit the training center once a week or every other week for a few hours. During this later stage, participants receive weekly assignments to be discussed in the weekly meetings. The general goal is that after two months of participating in the program individuals should start making successful job applications. However, participation in the program does not lower the job search requirements. While in the job search assistance program, unemployed workers must comply to the same minimum job applications requirements as when not being in the program. The job search assistance program should not last longer than one year, and individuals who start a new job during the program are offered to finish the program while working. The cost of the short job search assistance program is 500 euro per individual entering the program. The cost of the regular job search assistance program is 4000 euro for individuals above age 50 and for low-skilled individuals, and 3750 euro for individuals below age 50 .

The Participation Fund does not assign benefit recipients directly to programs, but outsources this task to a separate firm. This firm never has any personal contact with unemployed workers and receives only a limited amount of information when assigning them to treatment. The information consists of the social security number, gender, age, an indication for being low-skilled (i.e. previously in a subsidized job), entitlement duration to benefits, number of weekly hours of collecting benefits, and an indicator code for the previous employer. ${ }^{1}$ Two weeks prior to the start of the program the individual receives a letter explaining that she should enroll in a

\footnotetext{
${ }^{1}$ The policy is to avoid having individuals previously employed at the same institution in the same meeting groups.
} 
program. This letter also offers individuals to select one of the 11 locations.

In practice the policy guidelines concerning the timing of entering job search assistance were not followed strictly. This was due to administrative and communication issues between the Participation Fund and the external firm. ${ }^{2}$ There are cases where records got lost, where information was provided too late, and where notification letters were never sent. As we will show in the next section, this creates substantial variation in the assignment of the program. And, since the external firm never had any contact with benefit recipients, the variation in program assignment should be exogenous conditional on observed individual characteristics. We exploit the latter in the empirical analyses.

\section{Data}

In the empirical analyses we use administrative data from the Participation Fund. Our data concern all former employees from primary education institutions who started collecting unemployment insurance benefits between August 1, 2006 and April 1, 2008. Individuals are followed until their benefits entitlement ends (due to finding work or having exhausted their entitlement period) or until March 12, 2009. From the data we only consider those individuals who started collecting benefits within 30 days after being laid-off. According to the job search assistance program criteria, we leave out individuals who claimed benefits for less than eight hours per week. We also exclude individuals above age 60 since for them participation in the job search assistance program is voluntary.

From the data we drop three individuals who very often entered and exited unemployment during the observation period. We exclude 43 observations for which the date of entering the job search assistance program was unknown or prior to becoming unemployed. The latter might occur if the individual was still in the program from an earlier unemployment spell. Finally, we exclude 37 observations with an hourly wage in the previous job below three euro, which is far below the legally binding minimum wage.

The data contain 3064 individuals for which we only consider the first observed unemployment spell. Over $60 \%$ of the individuals are entitled to benefits for more than one year, and $40 \%$ have an entitlement period exceeding two years. As can be seen from Figure 1 almost 50\% of the inflow occurs in August, which is the start of a new school year. The outflow in much more spread over the year, although

\footnotetext{
${ }^{2}$ In the Netherlands, all individuals applying for unemployment insurance benefits should apply at the nationwide UI administration. This administration forwards files of workers from the primary education sector to the Participation Fund, which already causes a delay ranging from a few days to a few weeks.
} 
Figure 1: Seasonal variation in entry into and exit from unemployment.

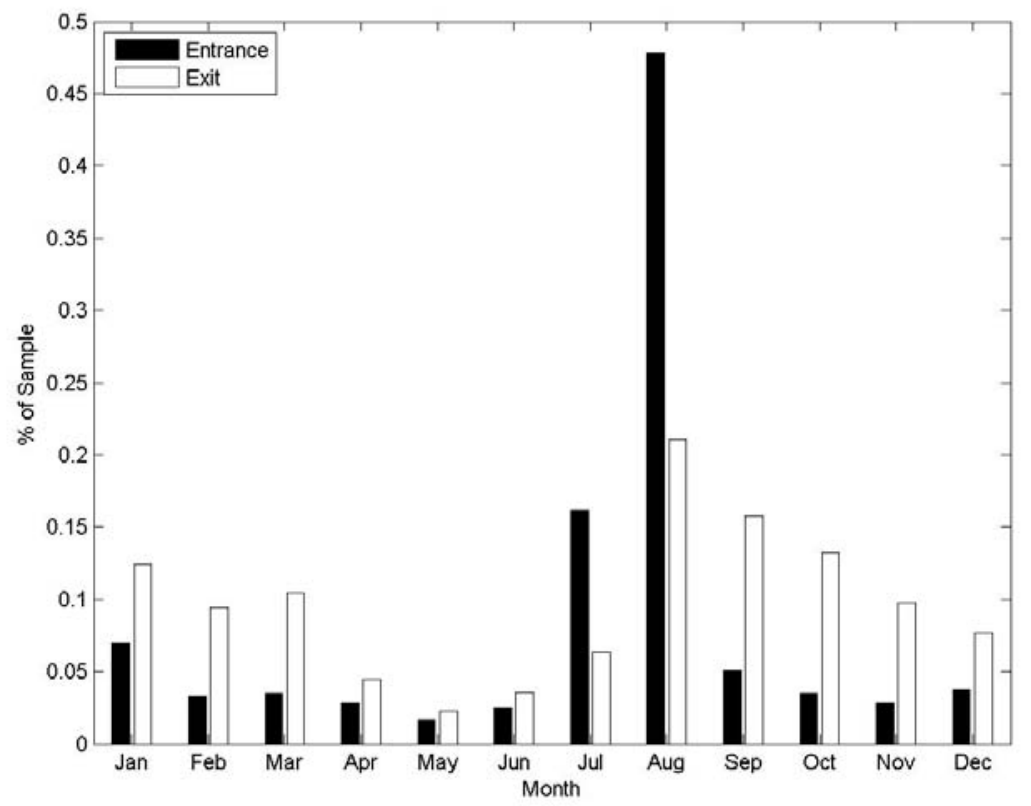

there is a decreasing trend over the school year. Figure 2a provides a KaplanMeier estimate for the exit to work. The median unemployment duration is about 21 weeks. Of the 3064 individuals, 862 entered the regular job search assistance program and 78 the short program. Figure $2 \mathrm{~b}$ shows the Kaplan-Meier estimate for entering a program. In the figure we distinguish two groups, those who should enter a program immediately (either older than 50 or low-skilled), and those who should enter after six months of unemployment (below 50 and not low-skilled). The figure clearly shows that the latter group enters the program, on average, later during the unemployment spell. Nevertheless, within each group there is still substantial variation in the moment of entering. This confirms that the external firm did not manage to correctly implement the rules for program assignment.

The data contain a limited set of individual characteristics. In Table 1 we provide some descriptive statistics. We distinguish between individuals who participated in a program during unemployment (participants) and those who did not (nonparticipants). The data contain the same individual characteristics as provided to the external firm who assigned the program. The participants are, on average, unemployed for more hours per week, and have a higher benefits level. This might be the direct consequence of the difference in age structure. Older workers are more likely to participate in a program, which follows the policy of assigning the programs. Of course, the different composition between the participants and the nonparticipants 
Figure 2: Kaplan-Meier estimates.

(a) Exit to work.

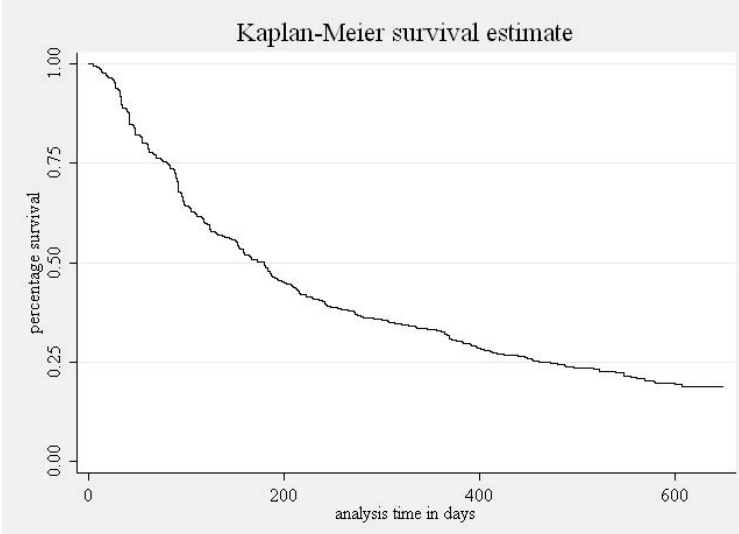

(b) Entering job search assistance.

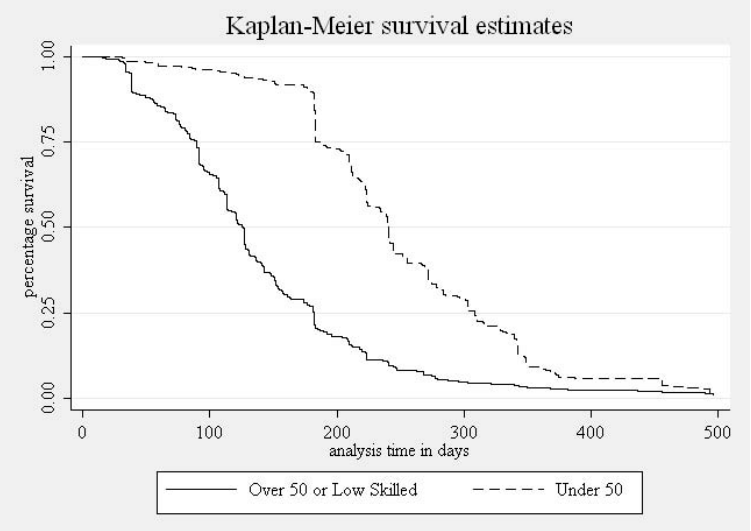

is not only the result of the assignment mechanism and the implementation of the external firm. Dynamic selection also plays an important role. Those individuals with adverse characteristics have, on average, longer unemployment durations and are thus more likely to have entered the job search assistance at some stage.

\section{Model for dynamic treatment evaluation}

In this section we briefly discuss a model for dynamic treatment evaluation. Our discussion fits within the more general discussion provided by Abbring and Heckman (2007). We highlight some issues relevant for actually estimating the dynamic treatment effects in our setting. In the next sections we apply different estimation methods, and provide a comparison of the empirical results.

\subsection{Theoretical framework}

Consider the case where we observe for each individual the duration $T>0$ of unemployment. We define the binary variables $Y_{t}$ as indicators for being unemployed $\left(Y_{t}=0\right)$ or employed $\left(Y_{t}=1\right)$ after $t$ periods, so $Y_{t}=I(T \leq t)$. This outcome variable describes the survival in unemployment, so $\mathrm{E}\left[Y_{t}\right]=1-\bar{S}(t)$, where $\bar{S}(t)$ is the survivor function $\operatorname{Pr}(T>t)$.

We focus on a situation in which individuals can receive a single treatment only once during the period of unemployment. All individuals in the data are eligible for entering treatment. However, the timing at which individuals receive treatment differs. Let $S>0$ denote the elapsed unemployment duration at the moment of entering treatment. Individuals might actually leave unemployment before starting 
Table 1: Descriptive statistics.

\begin{tabular}{lcc}
\hline \hline & $\begin{array}{c}\text { Program } \\
\text { participants }\end{array}$ & $\begin{array}{c}\text { Non- } \\
\text { participants }\end{array}$ \\
\hline Number of observations & 940 & 2124 \\
Median unemployment duration (in days) & 369 & \\
Median duration to program start (in days) & 156 & 96 \\
Unemployment hours per week & 29.9 & 26.7 \\
Benefits level (hourly) & $€ 12.8$ & $€ 10.4$ \\
Female & $64 \%$ & $85 \%$ \\
Age 20-35 & $9 \%$ & $59 \%$ \\
Age 35-50 & $46 \%$ & $29 \%$ \\
Age 50-65 & $45 \%$ & $12 \%$ \\
Low-skilled & $34 \%$ & $4 \%$ \\
\hline \hline
\end{tabular}

treatment. Let $D$ be a variable describing actual participation in treatment, $D=$ $I(S<T)$.

Ideally, one should measure the effect of treatment at time period $S$ on the residual unemployment duration $(T-S \mid T>S)$. This can easily be translated into a cost-benefit analysis in which the treatment costs are compared to expected changes in future benefits payments. Furthermore, considering this treatment effect for different values of $S$ is useful for improving the targeting of treatment to unemployed workers. However, data usually describe a limited observation period, so long unemployment durations are censored. The lack of observations in the right tail of the distribution of unemployment spells implies that we cannot estimate average durations. Instead, we focus on whether or not someone is still unemployed some period after providing treatment.

Let $Y_{1, t}^{*}(s)$ denote the potential unemployment status after $t$ periods if the individual was treated after $s$ periods. So even though we only consider a single treatment, it may have different effects when applied at different time periods. We impose that treatment only affects later outcomes

$$
Y_{1, t}^{*}(s)=Y_{1, t}^{*}\left(s^{\prime}\right) \quad \text { if } s \neq s^{\prime} \quad \forall t<s, s^{\prime}
$$

There is thus no causal dependence of outcomes on future treatments. This is the no-anticipation assumption described by Abbring and Van den Berg (2003) and also adopted by Fredriksson and Johansson (2008). No-anticipation rules out that, prior to the actual start of treatment, unemployed workers already change their job search behavior in response to being assigned to treatment. This rules out threat effects as, for example, measured by Black, Smith, Berger and Noel (2003). In their case 
unemployed workers are more likely to leave the benefits program once the have been informed about the actual start of a job search assistance program. A similar result is found by Crépon, Ferracci, Jolivet and Van den Berg (2010). However, imposing no-anticipation does not rule out ex-ante effects of the treatment. Individuals may know that they are exposed to the risk of having to participate in some treatment, and may, therefore, behave differently than in a system in which the treatment is absent. Justifying the no-anticipation assumption requires knowledge about the unemployed worker's information about participation in treatment prior to actually starting the treatment. In our case, the unemployed workers are informed (by letter) two weeks prior to the start of the job search assistance program. Our data contain some information about these letters which we exploit to justify the no-anticipation assumption (see the next subsection).

In a dynamic setting it is not immediately clear what the relevant counterfactual is. The most natural counterfactual is to consider the potential outcome $Y_{0, t}^{*}$, which is the outcome if the unemployed worker would not receive treatment prior to $t$. This implies $s>t$, and because of the no-anticipation assumption

$$
Y_{0, t}^{*}=Y_{1, t}^{*}(s) \quad \forall t<s
$$

The relevant treatment effect (on the treated) would be

$$
\Delta(t, s)=\mathrm{E}\left[Y_{1, t}^{*}(s)-Y_{0, t}^{*} \mid S=s, Y_{s}=0\right] \quad \text { with } t>s
$$

This treatment effect denotes the effect of providing treatment at $s$ on exit to work between $s$ and $t$ for those who were still unemployed at $s$. This is the ex-post effect of the treatment, so the effect of actually participating in the treatment on future outcomes. It should be noted that almost all empirical microeconometric literature focuses on ex-post effects and ignores ex-ante effects.

Unemployed workers treated at $s$ are thus compared to unemployed workers who (possibly) receive treatment after $t$. The main complication is that it is unclear which individuals qualify for the control group. There is, of course, the selection problem if treatment is not assigned randomly. However, an additional problem is that in a setting with ongoing entry in treatment it is not possible to identify which individuals did not receive treatment before $t$. In particular, for individuals who left unemployment between $s$ and $t$, it remains unobserved whether or not they would have received treatment before or after $t$. It is unclear how to deal with such observations. Gerfin and Lechner (2002) include these observations in the control group, but exclude individuals who are observed to have received treatment between $s$ and $t$. This causes a bias towards shorter unemployment spells in the control group, and treatment effects will be underestimated. Ignoring both types 
of observations does not solve the issue either as there is no exit observed in the control group between $s$ and $t$.

Sianesi (2004) suggests to consider as potential control group all individuals who receive treatment later than $s$. This implies that the treatment effect changes to

$$
\Delta^{*}(t, s)=\mathrm{E}\left[Y_{1, t}^{*}(s)-Y_{1, t}^{*}(>s) \mid S=s, Y_{s}=0\right] \quad \text { with } t>s
$$

where $Y_{1, t}^{*}(>s)$ is the potential employment outcome at $t$ for an unemployed worker not treated before or at $s$. This treatment effect describes the effect of entering treatment at $s$ compared to entering treatment at some later moment. The usefulness of this treatment effect is limited, mainly because the counterfactual outcomes and also the treatment effect depend on the future entry process into treatment. A cost-benefit analysis, for example, is not straightforward since it is unclear when individuals in the control group receive treatment.

Both approaches mentioned above to construct counterfactuals are mainly driven by the requirement to fit the evaluation problem within the standard (static) potential outcome model. Dynamic techniques can deal with such data problems more flexibly. Abbring and Van den Berg (2003) use a duration model framework in which they jointly model the length of the unemployment spell $T$ and the time until entry in treatment $S$. When imposing some functional form restrictions they can allow for selection on unobservables. Both Lechner (2009) and Fredriksson and Johansson (2008) discretize time and develop multi-period matching estimators assuming that selection is only on observables. A more practical issue is the choice of the unit of a time interval. In the next sections of this paper we discuss in more detail the application of different approaches to our data, and we compare the estimation results. This should provide insight in the advantages and disadvantages of the different estimators.

\subsection{Justifying no-anticipation}

In the previous subsection we introduced the no-anticipation assumption. Noanticipation implies that individuals do not change their behavior prior to entering the program once they know the exact time of starting the program. If unemployed workers receive information about the timing of entry in job search assistance far before the actual start, they might take this into account in their current job search decisions. Crépon, Ferracci, Jolivet and Van den Berg (2010) use notifications to test for anticipation of training programs. They find strong effects of the notifications already before the start of the training program. In their setting the average time between notification and entry in the program is almost three months. Our data also contain some information on invitation letters for the job search assistance program, 
which should be sent about two weeks prior to the start of job search assistance. However, this information is very incomplete. Letters are only recorded since April 2008 , so no information is available on the first two years of the observation period. There is also no guarantee that for the later period the information on the letters is complete. In total we observe that 279 letters were sent. We observe only four individuals who left unemployment in the two weeks prior to receiving the letter, but no one in the short period after receiving the letter. Furthermore, the data show that in almost all cases only 14 to 20 days elapsed between the sending of a letter and the start of a job search assistance program. This provides evidence in favor of the no-anticipation assumption in our setting.

The assumption of no-anticipation does not mean that individuals do not know about the assignment rules for the job search assistance program. Unemployed workers may be informed about the assignment rules. For example, an individual above age 50 may know that she should enter the program as soon as possible, but it is ruled out that individuals know the exact timing of entering the training. This also implies that individuals cannot manipulate their assignment to the program. Given the construction with the external agency assigning job search assistance, it is unlikely that individuals can either manipulate or obtain prior knowledge about their actual assignment. Unemployed workers do not know about the existence of the external firm, and the external firm only receives very limited information about each unemployed worker.

\section{Timing-of-events approach}

\subsection{The model}

We start by considering the timing-of-events approach proposed by Abbring and Van den Berg (2003) to estimate the effect of participating in job search assistance on exit from unemployment. This is a continuous-time method which allows for selection on unobservables. The idea is to jointly model reemployment $T$ and entry into treatment $S$ in a bivariate mixed proportional hazard rate model. Bonnal, Fougère and Serandon (1997) use a similar model to estimate the effect of job search training, and Van den Berg, Van der Klaauw and Van Ours (2004) to evaluate the effectiveness of benefits sanctions.

Consider an individual collecting unemployment insurance benefits for $t$ units of time. We assume that the exit rate can be characterized by observed characteristics $x$, unobserved characteristics $v_{u}$, the elapsed unemployment duration $t$ itself, and a variable indicating whether the individual already started participating in the job search assistance program $I(s<t)$, where $s$ is the moment at which an individual 
enters job search assistance. Furthermore, $v_{u}$ is assumed to be independent of $x$. The exit rate from unemployment at $t$ conditional on $x, v_{u}$ and $s$ is denoted by $\theta_{u}\left(t \mid x, v_{u}, s\right)$, and follows the familiar mixed proportional hazard specification

$$
\theta_{u}\left(t \mid x, v_{u}, s\right)=\lambda_{u}(t) \exp \left(x^{\prime} \beta_{u}+\delta \cdot I(s<t)+v_{u}\right)
$$

in which $\lambda_{u}(t)$ represents individual duration dependence.

The parameter $\delta$ describes the causal effect of participating in the job search assistance program. In the specification above, this is a multiplicative effect on the exit rate from unemployment. In Subsection 5.3 we show how we use this model to compute the dynamic treatment effects $\Delta(t, s)$ described in the previous section. In the model specification above $\delta$ is a permanent effect, which is the same for all individuals. This is most likely too strong an assumption. In the next subsection we allow $\delta$ to depend on individual characteristics $x$, the moment of starting the job search assistance program $s$, and the elapsed duration of job search assistance $t-s .^{3}$

Recall that our data contain the same information as the external agency had when assigning unemployed workers to job search assistance. If we include all individual characteristics known to this external agency in the vector $x$, then the moment of entering the training $s$ should be independent of unobservables $v_{u}$. We can test this by jointly modeling entry in the program and exit from unemployment. Therefore, consider an individual who has received unemployment insurance benefits for $t$ periods, and who did not start the job search assistance yet. The entry rate into job search assistance at $t$ conditional on observed and unobserved characteristics $x$ and $v_{s}$ is denoted by

$$
\theta_{s}\left(t \mid x, v_{s}\right)=\lambda_{s}(t) \exp \left(x^{\prime} \beta_{s}+v_{s}\right)
$$

where $x$ is again imposed to be independent of $v_{s}$. In this model specification, the entry rate in the job search assistance program is conditionally independent of the unobservables $v_{u}$ only if $v_{s}$ and $v_{u}$ are independent. When actually estimating the model we allow for dependence between $v_{u}$ and $v_{s}$ via the joint distribution $G\left(v_{u}, v_{s}\right)$, and test for independence.

The identification of the model framework is discussed at length in Abbring and Van den Berg (2003). The identification hinges on two key elements. First, proportionality in the hazard rates is necessary to identify the joint distribution of unobservables. This identification requirement thus imposes a restriction on the parametric specification. Second, the no-anticipation assumption discussed in the previous section is necessary. The model specifies the treatment effect as a change in the exit rate from unemployment at the start of the job search assistance program.

\footnotetext{
${ }^{3}$ Abbring and Van den Berg (2003) show that it is also possible to allow $\delta$ to depend on unobserved characteristics $v$.
} 
The model is estimated using maximum likelihood estimation. We, therefore, parameterize the duration dependence functions and the bivariate unobserved heterogeneity distribution using flexible specifications. We take both $\lambda_{u}(t)$ and $\lambda_{s}(t)$ to have a piecewise constant specification,

$$
\lambda_{i}(t)=\exp \left(\sum_{j=1,2, \ldots} \lambda_{i j} I_{j}(t)\right) \quad i=u, s
$$

where $j$ is a subscript for time intervals and $I_{j}(t)$ are time-varying dummy variables for each of the consecutive time intervals. Note that with an increasing number of time intervals any duration dependence pattern can be approximated arbitrarily closely.

We take the joint distribution of the unobserved heterogeneity terms $v_{u}$ and $v_{s}$ to be bivariate discrete with unrestricted mass-point locations for each term. Allowing $v_{u}$ and $v_{s}$ to have two points of support each $\left(v_{u}^{a}, v_{u}^{b}, v_{s}^{a}\right.$ and $v_{s}^{b}$ respectively), the distribution of $G\left(v_{u}, v_{s}\right)$ is

$$
\begin{array}{ll}
\operatorname{Pr}\left(v_{u}=v_{u}^{a}, v_{s}=v_{s}^{a}\right)=p_{1} & \operatorname{Pr}\left(v_{u}=v_{u}^{b}, v_{s}=v_{s}^{a}\right)=p_{3} \\
\operatorname{Pr}\left(v_{u}=v_{u}^{a}, v_{s}=v_{s}^{b}\right)=p_{2} & \operatorname{Pr}\left(v_{u}=v_{u}^{b}, v_{s}=v_{s}^{b}\right)=p_{4}
\end{array}
$$

with $0 \leq p_{i} \leq 1$ for $i=1, \ldots, 4$, and $p_{4}=1-p_{1}-p_{2}-p_{3}$. In this case it is easy to show that $v_{u}$ and $v_{s}$ are independent if and only if $\operatorname{cov}\left(v_{u}, v_{s}\right)=0$. The covariance of $v_{u}$ and $v_{s}$ equals

$$
\operatorname{cov}\left(v_{u}, v_{s}\right)=\left(p_{1} p_{4}-p_{2} p_{3}\right) \cdot\left(v_{u}^{a}-v_{u}^{b}\right) \cdot\left(v_{s}^{a}-v_{s}^{b}\right)
$$

In this case independence between $v_{u}$ and $v_{s}$ implies conditional independence between assignment to the job search assistance program and exit to work. It is always possible to allow for more than two mass-point locations but, as we will show the following section, the specification above is sufficiently flexible for our purpose.

\subsection{Parameter estimates}

Table 2 presents the parameter estimates for the timing-of-events model, both for the full sample and for the sample excluding the low-skilled workers. In both cases the effect of participating in the job search assistance program is negative and significant. Entering the program reduces the probability of finding work. In the full sample the exit rate from unemployment drops by about $29 \%=(\exp (-0.338)-1)$, and by about $36 \%$ for regular unemployed workers (excluding the low-skilled workers).

Low-skilled workers are less likely to exit unemployment and are significantly more likely to enter job search assistance. The latter is in agreement with the assignment policy of the program. Women are less likely to find work, but this is 
Table 2: Timing-of-events estimates.

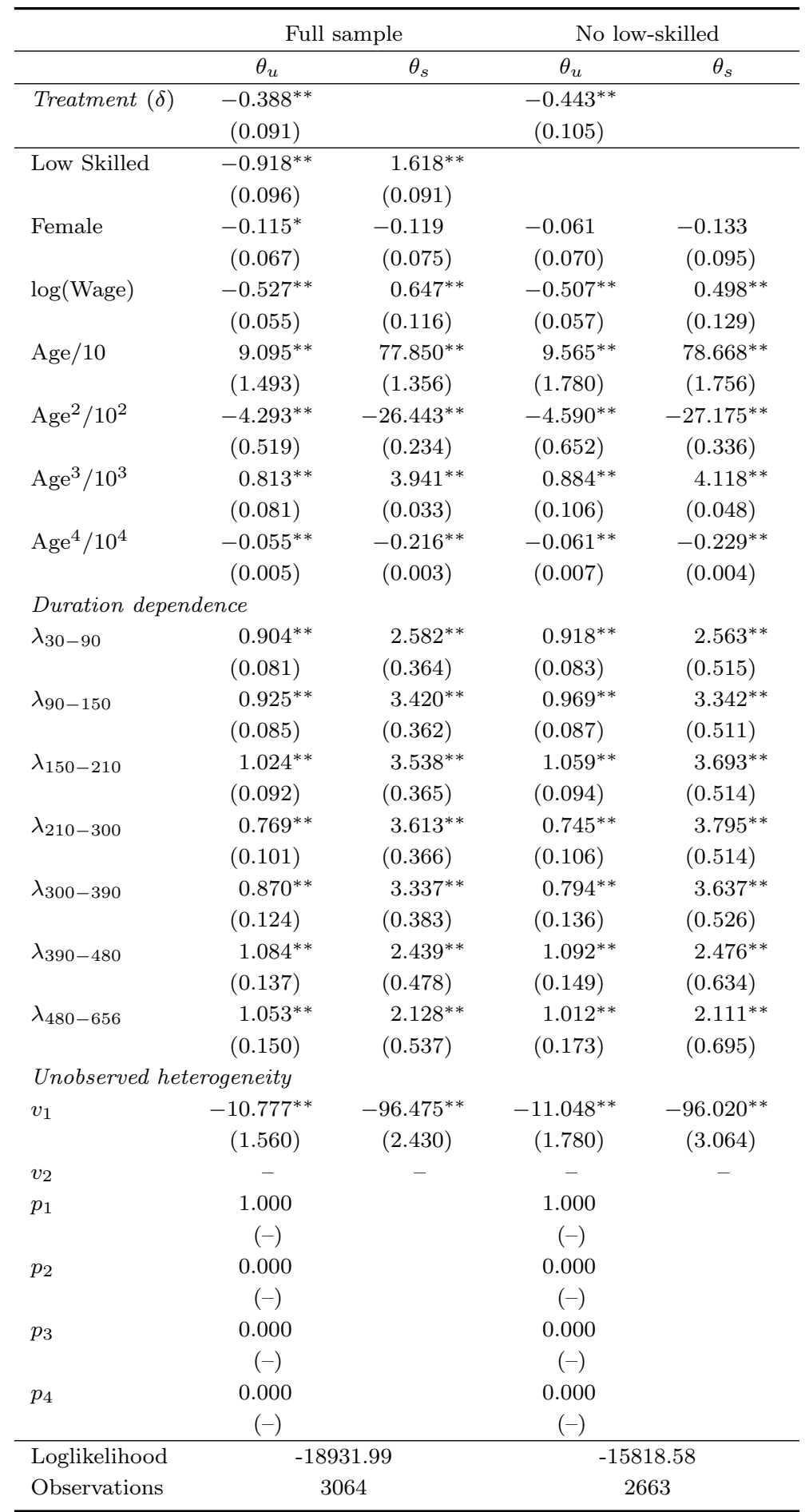

Note: $* *$ indicates significance at the $1 \%$ level, ${ }^{*}$ significance at the $5 \%$ level. Standard errors in parentheses. 
only significant in the full sample. The previous wage is negatively associated to finding work and positively related to entering the job search assistance program. We allow for a fourth-order polynomial in age. All terms have a significant effect both on exit from unemployment and program participation.

Both in the exit rate and the entry in job search assistance, the duration dependence pattern is relatively flat beyond 30 days of collecting benefits. This implies that during the first month of unemployment relatively few people find work, but later during the unemployment spell there is no decrease in the exit rate. The same holds for the entry in job search assistance.

The distribution of the unobserved heterogeneity is concentrated at a single mass point so there is no correlation between the unobserved heterogeneity $v_{u}$ in the exit rate and the unobserved heterogeneity $v_{s}$ in the entry rate in job search assistance. This confirms that conditional on observed characteristics assignment to the program is independent of the exit rate from unemployment, which is in agreement with the process of assigning job search assistance as described in Subsection 2.2.

We have tried including additional heterogeneity in the model. In particular, we have tried including calender-time effects and regional dummies. However, most of the covariate effects are insignificant and, more importantly, it did not change the parameter estimates. The latter is particularly true for the effects of participating in job search assistance.

Imposing proportionality of the hazard rates might be too strong. Low-skilled workers are very different from regular unemployed workers. Furthermore, individuals below and above age 50 have a different pattern of entry into the program. These different duration dependence patterns will most likely not be captured by a single dummy variable causing only a proportional shift in transition rates. To allow for these differences, we estimate the model separately for low-skilled workers, individuals above age 50 and those below age 50 .

Table 3 shows the parameter estimates for the three groups. The job search assistance has a negative effect on reemployment for all three groups but the effect is only significant for the no low-skilled individuals. Furthermore, the negative effect is almost twice as large for individuals over age 50. Recall that individuals over age 50 should enter the job search assistance early while individuals below age 50 are supposed to wait six months. To capture the timing of entrance into the program, we interact the effect of the program with the elapsed unemployment duration when entering. Table 4 shows that for all groups job search assistance has the largest negative effect when the unemployed worker enters early, and that this adverse effect becomes smaller the later the individual enters the program.

\footnotetext{
${ }^{4}$ If we exclude some regressors from our model, estimation results actually show dependent
} 
Table 3: Timing-of-events estimates by group.

\begin{tabular}{|c|c|c|c|c|c|c|}
\hline & \multicolumn{2}{|c|}{ Only low-skilled } & \multicolumn{2}{|c|}{$\begin{array}{c}\text { No low-skilled } \\
\text { Over } 50\end{array}$} & \multicolumn{2}{|c|}{$\begin{array}{c}\text { No low-skilled } \\
\text { Under } 50\end{array}$} \\
\hline & $\theta_{u}$ & $\theta_{s}$ & $\theta_{u}$ & $\theta_{s}$ & $\theta_{u}$ & $\theta_{s}$ \\
\hline Treatment $(\delta)$ & $\begin{array}{c}-0.195 \\
(0.285) \\
\end{array}$ & & $\begin{array}{c}-0.875^{* *} \\
(0.219) \\
\end{array}$ & & $\begin{array}{c}-0.414^{* *} \\
(0.148) \\
\end{array}$ & \\
\hline Female & $\begin{array}{c}-0.469^{*} \\
(0.220)\end{array}$ & $\begin{array}{c}-0.113 \\
(0.159)\end{array}$ & $\begin{array}{c}-0.120 \\
(0.170)\end{array}$ & $\begin{array}{c}-0.131^{* *} \\
(0.045)\end{array}$ & $\begin{array}{c}-0.040 \\
(0.080)\end{array}$ & $\begin{array}{c}0.156 \\
(0.167)\end{array}$ \\
\hline $\log ($ Wage $)$ & $\begin{array}{c}-1.408^{* *} \\
(0.332)\end{array}$ & $\begin{array}{c}0.687^{*} \\
(0.377)\end{array}$ & $\begin{array}{c}-0.481^{* *} \\
(0.197)\end{array}$ & $\begin{array}{l}0.646^{* *} \\
(0.077)\end{array}$ & $\begin{array}{c}-0.507^{* *} \\
(0.062)\end{array}$ & $\begin{array}{c}0.382^{*} \\
(0.202)\end{array}$ \\
\hline Age/10 & $\begin{array}{c}-24.256^{* *} \\
(9.252)\end{array}$ & $\begin{array}{c}-17.408^{* *} \\
(7.232)\end{array}$ & $\begin{array}{c}-49.799^{* *} \\
(4.440)\end{array}$ & $\begin{array}{l}7.563^{* *} \\
(1.822)\end{array}$ & $\begin{array}{l}32.359^{* *} \\
(3.130)\end{array}$ & $\begin{array}{c}-10.564 \\
(14.413)\end{array}$ \\
\hline $\mathrm{Age}^{2} / 10^{2}$ & $\begin{array}{c}8.285^{* *} \\
(2.366)\end{array}$ & $\begin{array}{c}6.308^{* *} \\
(1.663)\end{array}$ & $\begin{array}{l}30.951^{* *} \\
(2.731)\end{array}$ & $\begin{array}{c}-73.093^{* *} \\
(0.088)\end{array}$ & $\begin{array}{c}-15.122^{* *} \\
(1.343)\end{array}$ & $\begin{array}{c}10.032^{*} \\
(5.086)\end{array}$ \\
\hline $\mathrm{Age}^{3} / 10^{3}$ & $\begin{array}{c}-1.291^{* *} \\
(0.269)\end{array}$ & $\begin{array}{c}-0.978^{* *} \\
(0.131)\end{array}$ & $\begin{array}{c}-5.848^{* *} \\
(0.711)\end{array}$ & $\begin{array}{l}17.472^{* *} \\
(0.010)\end{array}$ & $\begin{array}{c}2.993^{* *} \\
(0.264)\end{array}$ & $\begin{array}{c}-2.654^{* *} \\
(0.804)\end{array}$ \\
\hline $\operatorname{Age}^{4} / 10^{4}$ & $\begin{array}{l}0.075^{* *} \\
(0.015)\end{array}$ & $\begin{array}{l}0.055^{* *} \\
(0.003)\end{array}$ & $\begin{array}{l}0.358^{* *} \\
(0.053)\end{array}$ & $\begin{array}{c}-1.183^{* *} \\
(0.003)\end{array}$ & $\begin{array}{c}-0.216^{* *} \\
(0.020)\end{array}$ & $\begin{array}{l}0.225^{* *} \\
(0.049)\end{array}$ \\
\hline \multicolumn{7}{|c|}{ Duration dependence } \\
\hline$\lambda_{30-90}$ & $\begin{array}{c}0.542 \\
(0.380)\end{array}$ & $\begin{array}{l}3.860^{* *} \\
(0.631)\end{array}$ & $\begin{array}{r}0.632 * \\
(0.290)\end{array}$ & $\begin{array}{l}2.456^{* *} \\
(0.518)\end{array}$ & $\begin{array}{l}0.945^{* *} \\
(0.086)\end{array}$ & 0.000 \\
\hline$\lambda_{90-150}$ & $\begin{array}{c}-0.142 \\
(0.440)\end{array}$ & $\begin{array}{l}5.444^{* *} \\
(0.645)\end{array}$ & $\begin{array}{l}1.159^{* *} \\
(0.306)\end{array}$ & $\begin{array}{l}3.460^{* *} \\
(0.514)\end{array}$ & $\begin{array}{c}0.949^{* *} \\
(0.091)\end{array}$ & $\begin{array}{l}0.815^{*} \\
(0.453)\end{array}$ \\
\hline$\lambda_{150-210}$ & $\begin{array}{c}0.282 \\
(0.454)\end{array}$ & $\begin{array}{l}5.266^{* *} \\
(0.650)\end{array}$ & $\begin{array}{c}0.912^{* *} \\
(0.386)\end{array}$ & $\begin{array}{c}3.571^{* *} \\
(0.521)\end{array}$ & $\begin{array}{l}1.100^{* *} \\
(0.099)\end{array}$ & $\begin{array}{l}2.861^{* *} \\
(0.358)\end{array}$ \\
\hline$\lambda_{210-300}$ & $\begin{array}{c}0.664 \\
(0.453)\end{array}$ & $\begin{array}{l}5.217^{* *} \\
(0.661)\end{array}$ & $\begin{array}{c}0.779^{*} \\
(0.454)\end{array}$ & $\begin{array}{l}3.301^{* *} \\
(0.535)\end{array}$ & $\begin{array}{c}0.784^{* *} \\
(0.112)\end{array}$ & $\begin{array}{l}3.434^{* *} \\
(0.341)\end{array}$ \\
\hline$\lambda_{300-390}$ & $\begin{array}{l}0.958^{*} \\
(0.470)\end{array}$ & $\begin{array}{c}3.799^{* *} \\
(0.859)\end{array}$ & $\begin{array}{l}1.014^{*} \\
(0.521)\end{array}$ & $\begin{array}{l}3.383^{* *} \\
(0.590)\end{array}$ & $\begin{array}{l}0.806^{* *} \\
(0.152)\end{array}$ & $\begin{array}{l}3.578^{* *} \\
(0.367)\end{array}$ \\
\hline$\lambda_{390-480}$ & $\begin{array}{l}0.837^{*} \\
(0.492)\end{array}$ & $\begin{array}{l}4.291^{* *} \\
(0.883)\end{array}$ & $\begin{array}{l}1.302^{*} \\
(0.569)\end{array}$ & $\begin{array}{c}2.446^{*} \\
(1.117)\end{array}$ & $\begin{array}{l}1.129^{* *} \\
(0.171)\end{array}$ & $\begin{array}{l}2.669^{* *} \\
(0.551)\end{array}$ \\
\hline$\lambda_{480-656}$ & $\begin{array}{c}0.976^{*} \\
(0.483)\end{array}$ & $\begin{array}{l}3.965^{* *} \\
(0.984)\end{array}$ & $\begin{array}{l}1.382^{*} \\
(0.666)\end{array}$ & $\begin{array}{l}5.779^{* *} \\
(0.509)\end{array}$ & $\begin{array}{l}0.997^{* *} \\
(0.209)\end{array}$ & $\begin{array}{l}1.817^{* *} \\
(0.762)\end{array}$ \\
\hline Unobserved het & rogeneity & & & & & \\
\hline$v_{1}$ & $\begin{array}{r}23.887^{*} \\
(12.548)\end{array}$ & $\begin{array}{c}9.592 \\
(10.502)\end{array}$ & $\begin{array}{c}-22.978 \\
(18.764)\end{array}$ & - & $\begin{array}{c}-29.120^{* *} \\
(2.780)\end{array}$ & - \\
\hline$v_{2}$ & - & $\begin{array}{c}5.671 \\
(10.498)\end{array}$ & $\begin{array}{c}-30.912 \\
(5865.900)\end{array}$ & $\begin{array}{c}335.300^{* *} \\
(6.521)\end{array}$ & - & $\begin{array}{c}-16.007 \\
(15.192)\end{array}$ \\
\hline$p_{1}$ & $\begin{array}{l}0.121^{* *} \\
(0.030)\end{array}$ & & $\begin{array}{c}0.000 \\
(-)\end{array}$ & & $\begin{array}{c}0.000 \\
(-)\end{array}$ & \\
\hline$p_{2}$ & $\begin{array}{c}0.000 \\
(-)\end{array}$ & & $\begin{array}{c}0.000 \\
(-)\end{array}$ & & $\begin{array}{c}0.000 \\
(-)\end{array}$ & \\
\hline$p_{3}$ & $\begin{array}{l}0.879^{* *} \\
(0.030)\end{array}$ & & $\begin{array}{c}0.892 \\
(0.916)\end{array}$ & & $\begin{array}{c}1.000 \\
(-)\end{array}$ & \\
\hline$p_{4}$ & $\begin{array}{c}0.000 \\
(-)\end{array}$ & & $\begin{array}{c}0.108 \\
(0.916)\end{array}$ & & $\begin{array}{c}0.000 \\
(-)\end{array}$ & \\
\hline $\begin{array}{l}\text { Loglikelihood } \\
\text { Observations }\end{array}$ & & $\begin{array}{l}3.42 \\
1\end{array}$ & & & & $\begin{array}{l}2.09 \\
92\end{array}$ \\
\hline
\end{tabular}

Note: ${ }^{* *}$ indicates significance at the $1 \%$ level, $*$ significance at the $5 \%$ level. Standard errors in parentheses. 
Table 4: Treatment effect depends on timing start of program.

\begin{tabular}{lcccc}
\hline \hline & & \multicolumn{3}{c}{ Treatment Effect $\delta$} \\
& Full Sample & Low Skilled & Over 50 no LS & Under 50 no LS \\
\hline Inflow within 4 months & $-0.678^{* *}$ & -0.375 & $-1.194^{*}$ & $-1.016^{*}$ \\
& $(0.138)$ & $(0.327)$ & $(0.556)$ & $(0.470)$ \\
Inflow 4 - 8 months & $-0.257^{* *}$ & 0.039 & -0.705 & $-0.425^{* *}$ \\
& $(0.108)$ & $(0.306)$ & $(0.546)$ & $(0.176)$ \\
Inflow after 8 months & -0.166 & 0.037 & -0.220 & -0.171 \\
& $(0.175)$ & $(0.526)$ & $(0.615)$ & $(0.219)$ \\
\hline \hline
\end{tabular}

Note: ${ }^{* *}$ indicates significance at the $1 \%$ level, ${ }^{*}$ significance at the $5 \%$ level. Standard errors in parentheses.

Table 5: Lock-in effects.

\begin{tabular}{lcccc}
\hline \hline & \multicolumn{4}{c}{ Treatment effect $\delta$} \\
& $F$ ull Sample & Low skilled (LS) & Over 50, not LS & Under 50, not LS \\
\hline$\delta_{t_{L I} \leq 60}$ & $-0.589^{* *}$ & -0.406 & $-0.943^{* *}$ & $-0.540^{*}$ \\
& $(0.151)$ & $(0.383)$ & $(0.274)$ & $(0.234)$ \\
$\delta_{60<t_{L I} \leq 365}$ & $-0.262^{* *}$ & -0.086 & $-0.855^{* *}$ & $-0.286^{*}$ \\
& $(0.102)$ & $(0.310)$ & $(0.174)$ & $(0.163)$ \\
$\delta_{365<t_{L I}}$ & $-0.568^{* *}$ & 0.014 & $-2.233^{* *}$ & $-0.972^{*}$ \\
& $(0.221)$ & $(0.458)$ & $(0.426)$ & $(0.562)$ \\
\hline \hline
\end{tabular}

Note: ${ }^{* *}$ indicates significance at the $1 \%$ level, ${ }^{*}$ significance at the $5 \%$ level. Standard errors in parentheses.

It is well known that job search assistance programs may cause lock-in effects, i.e. when being in the program individuals reduce their job search effort. The objective of the program was to prepare participants for making successful job applications within two months, with the maximum length of the program year. To capture locking-in, we allow the effect of job search assistance to depend on the elapsed duration in the program. We allow the program effect to be different during the first two months, between two months and one year and beyond one year. Table 5 shows that for regular unemployed workers the effect of the program is negative at any elapsed duration since the start of the program. This indicates that the negative effects which we found earlier are not only the consequence of a very large initial lock-in effect.

\subsection{Treatment effects}

Within the timing-of-events model, the causal effect of job search assistance describes a proportional shift in the exit rate. This does not directly translate into a statistic which is useful for policy purposes. Since the timing-of-events model provides a full parametric specification for the exit rate from unemployment and the entry into job search assistance, we can compute the effect of the program on the expected unobserved heterogeneity. 
unemployment duration. However, this is unattractive since it requires extrapolating the pattern of duration dependence beyond the observation period. Van den Berg and Van der Klaauw (2006) mention that expected unemployment durations are very sensitive on the details of this extrapolation.

Instead, we focus on the treatment effects $\Delta(t, s)$ discussed in Subsection 4.1. These treatment effects describe the change in the probability of finding work within $t$ periods after becoming unemployed due to entering job search assistance after $s$ periods (and conditional on still being unemployed at that moment). Using the timing-of-events model, for an unemployed worker with observed characteristics $x$ and unobserved characteristics $v_{u}$, this treatment effect can be written as

$$
\Delta(t, s ; x, v)=\frac{\exp \left(-\int_{0}^{t} \theta_{u}\left(z \mid x, t, v_{u}\right) d z\right)-\exp \left(-\int_{0}^{t} \theta_{u}\left(z \mid x, s, v_{u}\right) d z\right)}{\exp \left(-\int_{0}^{s} \theta_{u}\left(z \mid x, s, v_{u}\right)\right.}
$$

To obtain the population equivalent estimate, we average over the observed characteristics $x$ of all individuals in our sample and integrate over the distribution of unobserved heterogeneity. We use the delta method to compute standard errors around the treatment effects.

Table 6 shows the estimated employment probabilities and treatment effects. First, we use the estimation results from the (baseline) timing-of-events model with permanent homogeneous effects. The table first shows the effect of entering job search training after three months on employment after four and six months. The upper panel of the table shows that about $30 \%$ of the individuals leave unemployment within three months of starting to collect benefits. Without job search assistance almost $39 \%$ of the individuals find work within four months and about $52 \%$ within six months. If individuals are assigned to job search assistance after three months, the employment probability after four months reduces to around $36 \%$ and to almost $47 \%$ after six months. For $s=3$ the treatment effects $\Delta(t, s)$ thus equal -0.037 and -0.081 for $t=4$ and $t=6$, respectively. We also find significantly negative effects on employment for people entering job search assistance immediately and after six months. Immediately entry in job search assistance reduces the reemployment probability after six months by 0.108 . Entering the program after six months reduces the employment rate after nine months by 0.066 and after 12 month by 0.096 .

The second to fourth panel of Table 6 show the estimated models for the different groups. For low-skilled workers the effects are negative but insignificant. For both other groups participation in job search assistance significantly reduces the probability of being employed. The treatment effects are about the same for individuals above and below age 50. However, reemployment rates are much lower for individuals above age 50 . Therefore, one might argue that individuals above age 50 suffer 
Table 6: Average treatment effects for different subsamples and model specifications.

\begin{tabular}{|c|c|c|c|c|c|}
\hline & $(\mathrm{s}=3, \mathrm{t}=4)$ & $(\mathrm{s}=3, \mathrm{t}=6)$ & $(\mathrm{s}=\mathbf{0}, \mathrm{t}=\mathbf{6})$ & $(\mathrm{s}=6, \mathrm{t}=\mathbf{9})$ & $(\mathrm{s}=6, \mathrm{t}=12)$ \\
\hline \multicolumn{6}{|c|}{ Full Sample (baseline model) } \\
\hline \multirow[t]{2}{*}{$Y_{0, s}^{*}$} & 0.301 & 0.301 & 0.000 & 0.521 & 0.521 \\
\hline & $(0.008)$ & $(0.008)$ & $(-)$ & $(0.008)$ & $(0.008)$ \\
\hline \multirow[t]{2}{*}{$Y_{0, t}^{*}$} & 0.388 & 0.521 & 0.521 & 0.637 & 0.716 \\
\hline & $(0.007)$ & $(0.008)$ & $(0.008)$ & $(0.009)$ & $(0.010)$ \\
\hline \multirow{2}{*}{$Y_{1, t}^{*}(s)$} & 0.362 & 0.465 & 0.414 & 0.606 & 0.670 \\
\hline & $(0.009)$ & $(0.013)$ & $(0.024)$ & $(0.009)$ & $(0.010)$ \\
\hline \multirow[t]{2}{*}{$\Delta(\mathbf{s}, \mathbf{t})$} & $-0.037^{* *}$ & $-0.081^{* *}$ & $-0.108^{* *}$ & $-0.066^{* *}$ & $-0.096^{* *}$ \\
\hline & $(0.008)$ & $(0.018)$ & $(0.025)$ & $(0.015)$ & $(0.022)$ \\
\hline \multicolumn{6}{|c|}{ Low-skilled workers } \\
\hline \multirow[t]{2}{*}{$Y_{0, s}^{*}$} & 0.102 & 0.102 & 0.000 & 0.163 & 0.163 \\
\hline & $(0.016)$ & $(0.016)$ & $(-)$ & $(0.020)$ & $(0.020)$ \\
\hline \multirow[t]{2}{*}{$Y_{0, t}^{*}$} & 0.120 & 0.163 & 0.163 & 0.252 & 0.357 \\
\hline & $(0.016)$ & $(0.020)$ & $(0.020)$ & $(0.032)$ & $(0.050)$ \\
\hline \multirow[t]{2}{*}{$Y_{1, t}^{*}(s)$} & 0.117 & 0.153 & 0.137 & 0.237 & 0.328 \\
\hline & $(0.016)$ & $(0.019)$ & $(0.0327)$ & $(0.020)$ & $(0.023)$ \\
\hline \multirow[t]{2}{*}{$\Delta(\mathbf{s}, \mathbf{t})$} & -0.003 & -0.011 & -0.025 & -0.017 & -0.035 \\
\hline & $(0.005)$ & $(0.016)$ & $(0.036)$ & $(0.027)$ & $(0.053)$ \\
\hline \multicolumn{6}{|c|}{ Under age 50 and not low skilled } \\
\hline \multirow{2}{*}{$Y_{0, s}^{*}$} & 0.388 & 0.388 & 0.000 & 0.653 & 0.653 \\
\hline & $(0.010)$ & $(0.010)$ & $(-)$ & $(0.010)$ & $(0.010)$ \\
\hline \multirow[t]{2}{*}{$Y_{0, t}^{*}$} & 0.493 & 0.653 & 0.653 & 0.778 & 0.848 \\
\hline & $(0.009)$ & $(0.010)$ & $(0.010)$ & $(0.012)$ & $(0.014)$ \\
\hline \multirow[t]{2}{*}{$Y_{1, t}^{*}(s)$} & 0.460 & 0.583 & 0.519 & 0.743 & 0.803 \\
\hline & $(0.013)$ & $(0.024)$ & $(0.048)$ & $(0.016)$ & $(0.019)$ \\
\hline \multirow[t]{2}{*}{$\Delta(\mathbf{s}, \mathbf{t})$} & $-0.054^{* *}$ & $-0.114^{* *}$ & $-0.134^{* *}$ & $-0.100^{* *}$ & $-0.130^{* *}$ \\
\hline & $(0.016)$ & $(0.037)$ & $(0.047)$ & $(0.032)$ & $(0.034)$ \\
\hline \multicolumn{6}{|c|}{ Over age 50 and not low skilled } \\
\hline \multirow[t]{2}{*}{$Y_{0, s}^{*}$} & 0.118 & 0.118 & 0.000 & 0.291 & 0.291 \\
\hline & $(0.027)$ & $(0.027)$ & $(-)$ & $(0.025)$ & $(0.025)$ \\
\hline \multirow[t]{2}{*}{$Y_{0, t}^{*}$} & 0.186 & 0.291 & 0.291 & 0.393 & 0.488 \\
\hline & $(0.028)$ & $(0.025)$ & $(0.025)$ & $(0.033)$ & $(0.043)$ \\
\hline \multirow{2}{*}{$Y_{1, t}^{*}(s)$} & 0.147 & 0.197 & 0.138 & 0.336 & 0.385 \\
\hline & $(0.027)$ & $(0.026)$ & $(0.028)$ & $(0.024)$ & $(0.029)$ \\
\hline$\Delta(\mathbf{s}, \mathbf{t})$ & $-0.044^{* *}$ & $-0.107^{* *}$ & $-0.152^{* *}$ & $-0.080^{* *}$ & $-0.145^{* *}$ \\
\hline & $(0.014)$ & $(0.025)$ & $(0.032)$ & $(0.024)$ & $(0.038)$ \\
\hline Effect $d$ & endent on une & oloyment durat & $n$ at entering & & \\
\hline$Y_{0, s}^{*}$ & 0.302 & 0.302 & 0.000 & 0.523 & 0.523 \\
\hline & $(0.008)$ & $(0.008)$ & $(-)$ & $(0.008)$ & $(0.008)$ \\
\hline$Y_{0, t}^{*}$ & 0.389 & 0.523 & 0.523 & 0.640 & 0.716 \\
\hline & $(0.007)$ & $(0.008)$ & $(0.008)$ & $(0.009)$ & $(0.011)$ \\
\hline$Y_{1, t}^{*}(s)$ & 0.348 & 0.431 & 0.341 & 0.618 & 0.685 \\
\hline & $(0.009)$ & $(0.016)$ & $(0.033)$ & $(0.010)$ & $(0.012)$ \\
\hline$\Delta(\mathbf{s}, \mathbf{t})$ & $-0.058^{* *}$ & $-0.132^{* *}$ & $-0.183^{* *}$ & $-0.046^{*}$ & $-0.065^{*}$ \\
\hline & $(0.009)$ & $(0.023)$ & $(0.034)$ & $(0.019)$ & $(0.027)$ \\
\hline Effect $d$ & endent on elap & $d$ program durc & & & \\
\hline$Y_{0, s}^{*}$ & 0.301 & 0.301 & 0.000 & 0.522 & 0.522 \\
\hline & $(0.008)$ & $(0.008)$ & $(-)$ & $(0.008)$ & $(0.008)$ \\
\hline$Y_{0, t}^{*}$ & 0.388 & 0.522 & 0.522 & 0.637 & 0.713 \\
\hline & $(0.007)$ & $(0.008)$ & $(0.008)$ & $(0.009)$ & $(0.010)$ \\
\hline$Y_{1, t}^{*}(s)$ & 0.352 & 0.456 & 0.428 & 0.599 & 0.670 \\
\hline & $(0.010)$ & $(0.014)$ & $(0.025)$ & $(0.009)$ & $(0.010)$ \\
\hline$\Delta(\mathbf{s}, \mathbf{t})$ & $-0.052^{* *}$ & $-0.095^{* *}$ & $-0.093^{* *}$ & $-0.079^{* *}$ & $-0.089^{* *}$ \\
\hline & $(0.011)$ & $(0.019)$ & $(0.025)$ & $(0.016)$ & $(0.022)$ \\
\hline
\end{tabular}

** indicates significance at the $1 \%$ level, $*$ significance at the $5 \%$ level. Standard errors in parentheses. 
more from participating in job search assistance.

Next, we considered the model in which the effect of the job search assistance depends on the elapsed unemployment duration at the start of the program. The parameter estimates presented in the previous subsection indicated that the program's effect depends on the moment of entry. The treatment effect estimates in the fifth panel of Table 6 replicate this finding, showing that job search assistance has a more negative effect on the exit to work if entry is after three month compared to after six months. Compared to the model with homogenous constant treatment effects the estimated treatment effects change substantially. This emphasizes the importance of controlling for the moment of entry in the program.

The final model specification involved relating the effect of the program to time spent in the program. Recall that we did not find strong evidence in favor of differences between lock-in effect and post-program effects. The final panel of Table 6 shows the treatment effects corresponding to this model specification. It is not surprising that the results are not very different from the treatment effects in the baseline model with constant treatment effects.

\section{Propensity score methods}

The identification of the timing-of-events model relies on the no-anticipation assumption, but also requires that hazard rates are proportional. This second assumption might be restrictive because it imposes a functional form on the model. From the institutional setting we know that selection is only on observed characteristics. This was confirmed when estimating the timing-of-events model since we did not find any selection on unobservables. In this section we impose that selection is only on observables which allows us to relax parametric assumptions.

Selection on observables implies that conditional on observed characteristics, treatment assignment is independent of potential outcomes. In a setting with ongoing entry in the job search assistance program and a population in which all unemployed workers are entitled to the program, the conditional independence assumption is given by

$$
\left(Y_{1, t}^{*}(s) \quad \forall t, s>0\right) \perp S \mid X
$$

In our case the conditional independence assumption is satisfied as long as $X$ contains all characteristics known to the external firm assigning the job search assistance program. The conditional independence assumption is necessary for matching individuals entering the program with comparable unemployed workers who did not participate. 
The conditional independence assumption guarantees that

$$
\mathrm{E}\left[Y_{1, t}^{*}(s) \mid X\right]=\mathrm{E}\left[Y_{t} \mid X, S=s\right]
$$

The right-hand side takes the expected employment outcomes at $t$ for those individuals treated at $s$. In a dynamic setting, however, the moment of entry in the program is only observed for those unemployed workers who actually enter. In particular, for individuals who left unemployment prior to $s$ without having participated in the job search assistance program, we do not know if they would belong to the population with $S=s$. The usual approach is to consider only individuals who are still unemployed at time $s$ (i.e. $Y_{s}=0$ ), and who did not already enter job search assistance (i.e. $S \geq s$ ) (e.g. Gerfin and Lechner, 2002; Lalive, Van Ours and Zweimüller, 2008; and Sianesi, 2004). As in Subsection 4.1 we define our treatment effect of interest conditional on $Y_{s}=0$ and $S=s$.

Imposing only the conditional independence assumption does not guarantee that $\mathrm{E}\left[Y_{1, t}^{*}(s) \mid X, Y_{s}=0\right]$ equals $\mathrm{E}\left[Y_{t} \mid X, Y_{s}=0, S=s\right]$. This can be illustrated by the following example. Assume that potential outcomes depend on the observables $X$ and some other individual characteristics $U$, i.e. $Y_{1, t}^{*}(s ; X, U)$. The timing of entry into job search assistance only depends on $X$, i.e. $S(X)$, so the conditional independence assumption is satisfied. But there can still be dynamic selection if, for example, unemployed workers anticipate entry into the program and intensify job search effort. Within the stock of individuals who survive in unemployment for $s$ periods, those who start job search assistance at $s$ will then have different characteristics than those who enter later. Ridder (1984) showed that in a stock sample, for example $Y_{s}=0$, the distribution of unobserved characteristics $U$ depends on observed characteristics $X$. This implies that in case of anticipation at $s$, the moment of entering treatment $S$ is no longer independent of $U$, i.e. $S\left(X, U \mid Y_{s}=\right.$ $0) \neq S\left(X \mid Y_{s}=0\right)$. The consequence is that if the assumption of no-anticipation does not hold, a stronger conditional independence assumption is required to estimate dynamic treatment effects. In particular,

$$
\left(Y_{1, t}^{*}(s) \mid Y_{s}=0 \quad \forall t, s>0\right) \perp S \mid X, U
$$

which implies conditioning on all variables affecting the employment status. In many cases it is unlikely that data contain all characteristics which affect outcomes. In our case, this stronger assumption is unlikely to be satisfied because our data are not exceptionally rich on individual characteristics.

Because the moment of entry in the job search assistance program $S$ is a continuous process and we want to estimate the effect of entry in the program at a specific moment, we need to discretize time to obtain a group of unemployed workers entering at $S=s$. Let $\tau$ denote the unit of time. This implies that for all unemployed 
workers observed to enter the program between $s$ and $s+\tau$ we should find comparable controls. We use the propensity score $p_{s}(X)$ to match unemployed workers entering job search assistance at $s$ with those not entering at $s$. The propensity score is given by

$$
p_{s}(X)=\operatorname{Pr}\left(S<s+\tau \mid Y_{s}=0 ; S \geq s ; X\right)
$$

In the baseline case we take the unit of time $\tau$ equal to 30 days. The advantage of choosing $\tau$ relatively large is that it makes the size of the treatment group substantial, so more observations are used in the estimation. The disadvantage is that information is lost when aggregating time. In the sensitivity analyses we vary $\tau$ to get some idea about the robustness of the results.

We estimate the propensity score using a logit specification. As explanatory variables in the logit specification we use the same covariates as included in the timing-of-events model, so gender, a polynomial in age, the logarithm of the preunemployment wage and an indicator for being a low-skilled worker. As controls we take all untreated individuals whose propensity score differs less than 0.025 from the propensity score of the treated individual. If there are multiple controls for a single treated individual we weight the observations using a kernel with bandwidth $0.005 .{ }^{5}$

We checked the support of the propensity scores for the treated and controls. We find that the distribution of propensity scores change with $s$, as the decision to assign unemployed workers to job search assistance changes over the duration of unemployment. However, we do not find differences in the support between individuals actually entering job search assistance and those not entering.

In Subsection 4.1 we mentioned that within the control group there might be unemployed workers observed to enter job search assistance between $s+\tau$ and $t$. Sianesi (2004) modifies the treatment effect, such that it becomes the effect of entering at $s$ compared to later, which has the disadvantage that the treatment effect depends on the process of future entry into treatment. Lechner (1999) suggests to simulate the timing of entry for those individuals for which the moment of treatment entry is missing (and then remove the treatment and control observations with a simulated treatment between $s$ and $t$ ). However, this implies some conditioning on future outcomes. Fredriksson and Johansson (2008) advocate the use of duration models in discrete time. We follow Lalive, Van Ours and Zweimüller (2008) who combine a matching approach with estimating survivor functions based on duration models.

\footnotetext{
${ }^{5}$ Most of our results are robust against the choice of matching algorithm. For example, nearestneighbor matching gives in many cases very similar results.
} 
The treatment effect $\Delta(t, s)$ can we written as

$$
\Delta(t, s)=\mathrm{E}\left[Y_{1, t}^{*}(s) \mid S=s, Y_{s}=0\right]-\mathrm{E}\left[Y_{0, t}^{*} \mid S=s, Y_{s}=0\right]
$$

Since there is no right-censoring for the treatment group, we can estimate $\mathrm{E}\left[Y_{1, t}^{*}(s) \mid S=\right.$ $\left.s, Y_{s}=0\right]$ by the fraction of individuals who found work before $t$ having received treatment between $s$ and $s+\tau$. Within the matched control group we have to deal with observed entry in the treatment between $s+\tau$ and $t$. The no-anticipation assumption and the conditional independence assumption guarantee that conditional on $X$ all entry in the job search assistance program can be treated as independent right-censoring of the exit from unemployment. To estimate the counterfactual outcome it is thus crucial to condition on the observed characteristics $X$. Therefore, we apply the estimator

$$
\mathrm{E}\left[Y_{0, t}^{*} \mid S=\widehat{s, Y_{s}}=0, X\right]=1-\prod_{z=s+\tau}^{t} \operatorname{Pr}\left(Y_{z}=0 \mid S \widehat{>z}, Y_{z-\tau}=0, X\right)
$$

In our empirical analyses we use logit specifications for the survival probabilities $\operatorname{Pr}\left(Y_{z}=0 \mid S>z, Y_{z-\tau}=0, X\right)$. In particular, to minimize functional form assumption, we estimate for each $z$ a separate logit model.

A final issue is the computation of the standard errors. These must account for various sources of uncertainty around the treatment effects. The first source of uncertainty comes from the matching procedure. To estimate the variance generated by the matching we follow Lalive, Van Ours and Zweimüller (2008) and apply subsampling. Additionally, there is variation because the survivor functions for both the treatment and the matched control group are based on estimated Logit specifications. We can use the Delta method to estimate the variance of these separate survivor functions and the resulting treatment effect for a given matched sample. We add both variances to estimate the variance of the treatment effect.

\subsection{Treatment effects}

Table 7 shows the estimation results for the propensity score matching approach. The first panel of the table shows the results for the baseline case. As in the timing-of-events model, we find negative treatment effects for all five treatment effects. However, in none of the cases are the treatment effects significant. The main reason for the insignificance are the relatively high standard errors, which are caused by estimating the logit functions underlying the untreated outcomes. Furthermore, the standard errors in the third column reflect the small sample of entrances into training during the first month of unemployment. The use of the logit functions is necessary to account for right-censoring due to later entry in the 
Table 7: Results from propensity score methods.

\begin{tabular}{|c|c|c|c|c|c|}
\hline & $(\mathrm{s}=3, \mathrm{t}=4)$ & $(\mathrm{s}=3, \mathrm{t}=6)$ & $(\mathrm{s}=\mathbf{0}, \mathrm{t}=\mathbf{6})$ & $(\mathrm{s}=6, \mathrm{t}=\mathbf{9})$ & $(\mathrm{s}=6, \mathrm{t}=12)$ \\
\hline \multicolumn{6}{|c|}{ Baseline model } \\
\hline \multirow{2}{*}{$Y_{0, s}^{*}$} & 0.307 & 0.307 & 0.000 & 0.563 & 0.563 \\
\hline & $(0.011)$ & $(0.011)$ & $(-)$ & $(0.014)$ & $(0.014)$ \\
\hline \multirow{2}{*}{$Y_{0, t}^{*}$} & 0.360 & 0.393 & 0.384 & 0.668 & 0.710 \\
\hline & $(0.041)$ & $(0.080)$ & $(0.315)$ & $(0.079)$ & $(0.121)$ \\
\hline \multirow[t]{2}{*}{$Y_{1, t}^{*}(s)$} & 0.322 & 0.348 & 0.222 & 0.620 & 0.702 \\
\hline & $(0.013)$ & $(0.024)$ & $(0.155)$ & $(0.037)$ & $(0.051)$ \\
\hline \multirow[t]{2}{*}{$\Delta(\mathbf{s}, \mathbf{t})$} & -0.054 & -0.065 & -0.162 & -0.110 & -0.019 \\
\hline & $(0.043)$ & $(0.084)$ & $(0.350)$ & $(0.089)$ & $(0.132)$ \\
\hline \multicolumn{6}{|c|}{ No heterogeneity in exit probabilities } \\
\hline \multirow[t]{2}{*}{$Y_{0, s}^{*}$} & 0.307 & 0.307 & 0.000 & 0.563 & 0.563 \\
\hline & $(0.011)$ & $(0.011)$ & $(-)$ & $(0.014)$ & $(0.014)$ \\
\hline \multirow[t]{2}{*}{$Y_{0, t}^{*}$} & 0.360 & 0.396 & 0.403 & 0.669 & 0.711 \\
\hline & $(0.024)$ & $(0.034)$ & $(0.201)$ & $(0.051)$ & $(0.066)$ \\
\hline \multirow{2}{*}{$Y_{1, t}^{*}(s)$} & 0.322 & 0.348 & 0.222 & 0.620 & 0.702 \\
\hline & $(0.013)$ & $(0.024)$ & $(0.152)$ & $(0.037)$ & $(0.051)$ \\
\hline \multirow[t]{2}{*}{$\Delta(\mathbf{s}, \mathbf{t})$} & $-0.054^{*}$ & -0.069 & -0.181 & -0.113 & -0.021 \\
\hline & $(0.027)$ & $(0.042)$ & $(0.251)$ & $(0.064)$ & $(0.085)$ \\
\hline \multicolumn{6}{|c|}{ Ignoring later entry in treatment } \\
\hline \multirow[t]{2}{*}{$Y_{0, s}^{*}$} & 0.307 & 0.307 & 0.000 & 0.563 & 0.563 \\
\hline & $(0.011)$ & $(0.011)$ & $(-)$ & $(0.014)$ & $(0.014)$ \\
\hline \multirow[t]{2}{*}{$Y_{0, t}^{*}$} & 0.360 & 0.398 & 0.335 & 0.661 & 0.688 \\
\hline & $(0.024)$ & $(0.030)$ & $(0.166)$ & $(0.045)$ & $(0.049)$ \\
\hline \multirow[t]{2}{*}{$Y_{1, t}^{*}(s)$} & 0.322 & 0.342 & 0.222 & 0.620 & 0.701 \\
\hline & $(0.013)$ & $(0.020)$ & $(0.152)$ & $(0.037)$ & $(0.051)$ \\
\hline \multirow[t]{2}{*}{$\Delta(\mathbf{s}, \mathbf{t})$} & $-0.054^{*}$ & $-0.080^{*}$ & -0.113 & -0.094 & 0.028 \\
\hline & $(0.027)$ & $(0.037)$ & $(0.223)$ & $(0.060)$ & $(0.072)$ \\
\hline \multicolumn{6}{|c|}{ Excluding later treated from control group } \\
\hline \multirow[t]{2}{*}{$Y_{0, s}^{*}$} & 0.307 & 0.307 & 0.000 & 0.563 & 0.563 \\
\hline & $(0.011)$ & $(0.011)$ & $(-)$ & $(0.014)$ & $(0.014)$ \\
\hline \multirow[t]{2}{*}{$Y_{0, t}^{*}$} & 0.360 & 0.409 & 0.353 & 0.689 & 0.704 \\
\hline & $(0.024)$ & $(0.033)$ & $(0.168)$ & $(0.049)$ & $(0.054)$ \\
\hline \multirow[t]{2}{*}{$Y_{1, t}^{*}(s)$} & 0.322 & 0.338 & 0.222 & 0.620 & 0.701 \\
\hline & $(0.013)$ & $(0.019)$ & $(0.152)$ & $(0.037)$ & $(0.051)$ \\
\hline \multirow[t]{2}{*}{$\Delta(\mathbf{s}, \mathbf{t})$} & $-0.054^{*}$ & $-0.103^{* *}$ & -0.131 & $-0.160^{*}$ & -0.008 \\
\hline & $(0.027)$ & $(0.039)$ & $(0.225)$ & $(0.065)$ & $(0.080)$ \\
\hline
\end{tabular}

Matching taken over 30 day interval $[s, s+30)$.

** indicates significance at the $1 \%$ level, * significance at the $5 \%$ level.

Matching and Logit functions include the same covariates as the timing of events model. 
program, which is only independent of the exit from unemployment conditional on the individual characteristics $X$. Fredriksson and Johansson (2008) do not discuss including covariates in the exit probabilities. In the second panel of the table we follow this approach. This hardly affects the estimates for the average potential untreated outcomes $Y_{0, t}^{*}$ and the treatment effects $\Delta(s, t)$. The standard errors are, however, reduced substantially.

Most complications are caused by unemployed workers entering job search assistance between $s+\tau$ and $t$, which confounds the definition of the control group. Sianesi (2004) suggests to ignore later entry in job search assistance and to include unemployed workers entering job search assistance between $s+\tau$ and $t$ in the control group. The alternative is to exclude individuals with observed entry in the job search assistance program between $s+\tau$ and $t$ from the evaluation. In the bottom two panels of Table 7 we report the results from both approaches. Standard errors are reduced compared to the previous results. Furthermore, excluding unemployed workers who receive later treatment seems to generate a larger bias in the estimated treatment effects than ignoring later entry. This is particularly true for the treatment effects reported in the second and the fourth column.

When applying the propensity score matching methods we need to discretize time. Above we fixed the unit of time $(\tau)$ to 30 days. In Table 8 we show estimation results for different units of time. Reducing the unit of time, for example, to 15 days causes that sample sizes become too small. Therefore, we focus on increasing the unit of time to 45 and 90 days. There are two important consequences of increasing the unit of time. First, treatment effects become more negative. And second, standard errors reduce mainly because treated and matched control groups contain more observations. So treatment effects become significant and are different from the treatment effects found using smaller units of time. The propensity score matching method thus lacks in this case robustness against the choice of the unit of time.

\section{Regression discontinuity}

Recall that regular workers (i.e. those who are not low-skilled) who are younger than 50 when becoming unemployed only enter the job search assistance program after having collected benefits for six months. Unemployed workers 50 years and older should enter the program immediately after becoming unemployed. We focus here on these regular unemployed workers and exploit the policy discontinuity at age 50. In Section 3 we showed that there is a substantial difference in the entry process in the program between unemployed workers below and above age 50. However, 
Table 8: Estimation results from propensity score matching with different units of time.

\begin{tabular}{|c|c|c|c|c|c|}
\hline & $(\mathrm{s}=3, \mathrm{t}=4)$ & $(\mathrm{s}=3, \mathrm{t}=6)$ & $(\mathrm{s}=0, \mathrm{t}=6)$ & $(\mathrm{s}=6, \mathrm{t}=9)$ & $(\mathrm{s}=6, \mathrm{t}=12)$ \\
\hline \multicolumn{6}{|l|}{$\tau=30$} \\
\hline \multirow[t]{2}{*}{$Y_{0, s}^{*}$} & 0.307 & 0.307 & 0.000 & 0.563 & 0.563 \\
\hline & $(0.011)$ & $(0.011)$ & $(-)$ & $(0.014)$ & $(0.014)$ \\
\hline \multirow[t]{2}{*}{$Y_{0, t}^{*}$} & 0.360 & 0.393 & 0.384 & 0.668 & 0.710 \\
\hline & $(0.041)$ & $(0.080)$ & $(0.315)$ & $(0.079)$ & $(0.121)$ \\
\hline \multirow[t]{2}{*}{$Y_{1, t}^{*}(s)$} & 0.322 & 0.348 & 0.222 & 0.620 & 0.702 \\
\hline & $(0.013)$ & $(0.024)$ & $(0.155)$ & $(0.037)$ & $(0.051)$ \\
\hline \multirow[t]{2}{*}{$\Delta(\mathbf{s}, \mathbf{t})$} & -0.054 & -0.065 & -0.162 & -0.110 & -0.019 \\
\hline & $(0.043)$ & $(0.084)$ & $(0.350)$ & $(0.089)$ & $(0.132)$ \\
\hline \multicolumn{6}{|l|}{$\tau=45$} \\
\hline \multirow{2}{*}{$Y_{0, s}^{*}$} & & 0.307 & 0.000 & 0.563 & 0.563 \\
\hline & & $(0.011)$ & $(-)$ & $(0.014)$ & $(0.014)$ \\
\hline \multirow[t]{2}{*}{$Y_{0, t}^{*}$} & & 0.404 & 0.267 & 0.667 & 0.699 \\
\hline & & $(0.043)$ & $(0.091)$ & $(0.043)$ & $(0.072)$ \\
\hline \multirow[t]{2}{*}{$Y_{1, t}^{*}(s)$} & & 0.345 & 0.067 & 0.601 & 0.663 \\
\hline & & $(0.016)$ & $(0.031)$ & $(0.024)$ & $(0.035)$ \\
\hline \multirow[t]{2}{*}{$\Delta(\mathbf{s}, \mathbf{t})$} & & -0.085 & $-0.200^{*}$ & $-0.150^{* *}$ & -0.081 \\
\hline & & $(0.047)$ & $(0.096)$ & $(0.052)$ & $(0.083)$ \\
\hline \multicolumn{6}{|l|}{$\tau=90$} \\
\hline \multirow[t]{2}{*}{$Y_{0, s}^{*}$} & & 0.307 & 0.000 & 0.563 & 0.563 \\
\hline & & $(0.011)$ & $(-)$ & $(0.014)$ & $(0.014)$ \\
\hline \multirow[t]{2}{*}{$Y_{0, t}^{*}$} & & 0.426 & 0.249 & 0.677 & 0.713 \\
\hline & & $(0.020)$ & $(0.046)$ & $(0.024)$ & $(0.034)$ \\
\hline \multirow{2}{*}{$Y_{1, t}^{*}(s)$} & & 0.335 & 0.0717 & 0.598 & 0.652 \\
\hline & & $(0.012)$ & $(0.022)$ & $(0.020)$ & $(0.029)$ \\
\hline \multirow[t]{2}{*}{$\Delta(\mathbf{s}, \mathbf{t})$} & & $-0.131^{* *}$ & $-0.178^{* *}$ & $-0.180^{* *}$ & $-0.138^{* *}$ \\
\hline & & $(0.024)$ & $(0.051)$ & $(0.034)$ & $(0.047)$ \\
\hline
\end{tabular}

** indicates significance at the $1 \%$ level, ${ }^{*}$ significance at the $5 \%$ level.

We estimate the matching and Logit functions with the same covariates as in the timing of events model. 
within both groups there is a large variation in the moment of entering the job search assistance program. The regression-discontinuity design is, therefore, fuzzy (e.g. Hahn, Todd and Van der Klaauw, 2001).

The analysis of a fuzzy regression-discontinuity design is not straightforward in a dynamic setting. At the start of their unemployment spell individuals know that their age affects the entry rate in the program. Forward-looking individuals may use this information which means being above or below the age threshold may not be a valid instrument for program entry. This has also been recognized by Rosenzweig and Wolpin (2000), who criticize the use of instrumental variables in dynamic settings. Abbring and Van den Berg (2005) argue that an indicator for being above or below the age threshold is a special regressor rather than an instrumental variable.

We can either use a continuous-time duration model or we can discretize time to relax functional-form restrictions. The continuous-time regression-discontinuity approach fits within the instrumental-variable duration model proposed by Abbring and Van den Berg (2005). This framework closely follows the timing-of-events model, but it exploits the policy discontinuity at age 50 . The variable indicating if at the start of unemployment an individual is 50 years or older is a special regressor. This variable only affects the exit rate from unemployment until the moment of entry in job search assistance. The intuition is that information about the entry process in the program is valuable only until someone actually enters the job search assistance program. Using a mixed proportional hazard rate for exit from unemployment, this gives the specification

$$
\theta_{u}\left(t \mid x, v_{u}, t_{s}\right)=\lambda_{u}(t) \exp \left(x^{\prime} \beta_{u}+\eta_{u} \cdot 50^{+} \cdot I\left(t \leq t_{s}\right)+\delta \cdot I\left(t>t_{s}\right)+v_{u}\right)
$$

where $50^{+}$is an indicator function for being 50 years or older. Obviously the age of the individual (at the start of the unemployment spell) is also included in the vector of individual characteristics $x$ (but again as a polynomial).

The parameter $\eta_{u}$ provides some insight into the presence of ex-ante effects of the job search assistance program. If unemployed workers dislike participation in job search assistance and have a high risk of being assigned to the program, they might increase their job search effort to leave unemployment before actually being assigned to the program. In that case $\eta_{u}$ will be positive, since individuals age 50 and older are more likely to be assigned to job search assistance early during the unemployment spell. The presence of ex-ante effects does not violate the no-anticipation assumption, which states that individuals should not change their behavior in response to knowing the exact moment of entering the program. The ex-ante effect described by $\eta_{u}$ is thus also different from, for example, the threat effect estimated by Black, Smith, Berger and Noel (2003). 
Regression-discontinuity methods allow for selection on unobservables. Therefore, like in the timing-of-events method, we jointly model the entry rate into the job search assistance program which also depends on the variable indicating if the individual was 50 years or older at the moment of becoming unemployed,

$$
\theta_{s}\left(t \mid x, v_{s}\right)=\lambda_{s}(t) \exp \left(x^{\prime} \beta_{s}+\eta_{s} \cdot 50^{+}+v_{s}\right)
$$

The identification of the treatment effect $\delta$ hinges on the mixed proportional hazard rate structure and the no-anticipation assumption. The policy discontinuity only identifies the parameter $\eta_{u}$. We parameterize this bivariate duration model similarly to the timing-of-events model and estimate the model using maximum likelihood estimation.

We can again try to relax the parametric structure of the model by discretizing time. To do so we rely on static methods for analyzing a fuzzy regressiondiscontinuity design, which translate into an instrumental-variable approach (e.g. Hahn, Todd and Van der Klaauw, 2003). The conditions for instrumental variables are

$$
Y_{1, t}^{*}(s) \perp 50^{+} \mid X \quad \text { and } \quad S\left(50^{+}, X\right) \neq S\left(50^{-}, X\right)
$$

The first condition implies that conditional on covariates $X$ the age threshold does not affect potential outcomes. The second condition implies that the age threshold has a nontrivial effect on the timing of entering job search assistance. Note that the continuous-time regression-discontinuity model discussed above violates the first (conditional independence) assumption of the instrumental variable if $\eta_{u} \neq 0$.

Since the fuzzy regression-discontinuity design is an instrumental variables approach, it measures the effect of participating in job search assistance for the compliers. We denote the compliers by $C=c$ and the marginal treatment effect we evaluate is

$$
\Delta_{c}(t, s ; X)=\mathrm{E}\left[Y_{1, t}^{*}(s) \mid Y_{s}=0, X, C=c\right]-\mathrm{E}\left[Y_{0, t}^{*} \mid Y_{s}=0, X, C=c\right]
$$

We should use the population distribution of $X$ to obtain the population equivalent of this treatment effect. We follow Imbens and Rubin (1997), who characterize the marginal outcome distributions for compliers in an instrumental variable setting. The expected potential treated outcome equals

$$
\begin{aligned}
\mathrm{E}\left[Y_{1, t}^{*}(s) \mid Y_{s}=0, X, C=c\right] & =\frac{1}{\operatorname{Pr}\left(S=s \mid 50^{+}, Y_{s}=0, X\right)-\operatorname{Pr}\left(S=s \mid 50^{-}, Y_{s}=0, X\right)} \\
\times\left\{\operatorname{Pr}\left(S=s \mid 50^{+}, Y_{s}=0, X\right) \mathrm{E}\left[Y_{t} \mid S=s, 50^{+}, Y_{s}=0, X\right]\right. & \\
- & \left.\operatorname{Pr}\left(S=s \mid 50^{-}, Y_{s}=0, X\right) \mathrm{E}\left[Y_{t} \mid S=s, 50^{-}, Y_{s}=0, X\right]\right\}
\end{aligned}
$$


and the expected potential untreated outcome is

$$
\begin{aligned}
\mathrm{E}\left[Y_{0, t}^{*} \mid Y_{s}=0, X, C=c\right] & =\frac{1}{\operatorname{Pr}\left(S=s \mid 50^{+}, Y_{s}=0, X\right)-\operatorname{Pr}\left(S=s \mid 50^{-}, Y_{s}=0, X\right)} \\
\times\left\{\operatorname { P r } \left(S>s \mid 50^{-}, Y_{s}\right.\right. & =0, X) \mathrm{E}\left[Y_{t} \mid S>t, 50^{-}, Y_{s}=0, X\right] \\
& \left.-\operatorname{Pr}\left(S>s \mid 50^{+}, Y_{s}=0, X\right) \mathrm{E}\left[Y_{t} \mid S>t, 50^{+}, Y_{s}=0, X\right]\right)
\end{aligned}
$$

When applying regression-discontinuity estimation we condition on $Y_{s}=0$ and $S \geq s$ for the same reasons as when using propensity score matching, i.e. for individuals who left unemployment without having entered the job search assistance program we do not know $S$. We also have to maintain the no-anticipation assumption otherwise the treatment and control groups have different processes of dynamic selection. However, the question arises under which conditions the variable $50^{+}$is still a valid instrumental variable for treatment at $s$ within the sample $Y_{s}=0$ and $S \geq s$. The requirement is that $Y_{1, t}^{*}(s)$ be independent of $50^{+}$conditional on $Y_{s}=0$ and $S \geq s$. Assume again that potential outcomes depend not only on observables $X$, but also on other variables $U$, so $Y_{1, t}^{*}(s ; X, U)$. Furthermore, the entry in job search assistance also depends on unobservables $V$ and is written as $S\left(50^{+}, X, V\right)$. The fuzzy regression discontinuity requires the following conditional independence assumption

$$
\left(Y_{1, t}^{*}\left(s^{\prime}\right) \mid Y_{s}=0, S \geq s, \quad \forall t, s^{\prime} \geq s>0\right) \perp 50^{+} \mid X, U, V
$$

This assumption implies that, at each moment $s$, the instrument is randomly assigned within the population of survivors in unemployment who had not yet participated in the program. This assumption is stricter than in the continuous-time model discussed above. But in this case the policy discontinuity actually identifies the treatment effect, while in the continuous-time model the policy discontinuity only identified the parameter $\eta_{u}$.

The implementation of the estimator is not straightforward. In particular, estimating the expectations $\mathrm{E}\left[Y_{t} \mid S>s, 50^{+}, Y_{s}=0, X\right]$ and $\mathrm{E}\left[Y_{t} \mid S>t, 50^{-}, Y_{s}=0, X\right]$ is somewhat complicated due to the issue of program entry between $s$ and $t$. In this case we follow the same approach as discussed in the previous subsection. So again we estimate logit models for exit from unemployment for each time interval with length $\tau$. Of course, this relies on the assumption that, conditional on the covariates $X$ included in the logit specifications, exit from unemployment is independent of entry in job search assistance. So again we rely on the conditional independence assumption. 
Table 9: Continuous-time regression-discontinuity estimates for regular unemployed workers between age 40 and 60 .

\begin{tabular}{|c|c|c|}
\hline & $\theta_{u}$ & $\theta_{s}$ \\
\hline Treatment $(\delta)$ & $\begin{array}{c}-0.653^{* *} \\
(0.261)\end{array}$ & \\
\hline Older than 50 years $(\eta)$ & $\begin{array}{c}0.103 \\
(0.195)\end{array}$ & $\begin{array}{l}1.623^{* *} \\
(0.288)\end{array}$ \\
\hline Gender & $\begin{array}{c}-0.233^{*} \\
(0.123)\end{array}$ & $\begin{array}{c}-0.146 \\
(0.139)\end{array}$ \\
\hline $\log ($ Wage $)$ & $\begin{array}{c}-0.636^{* *} \\
(0.132)\end{array}$ & $\begin{array}{c}0.769^{* *} \\
(0.175)\end{array}$ \\
\hline Age/10 & $\begin{array}{c}0.102 \\
(33.853)\end{array}$ & $\begin{array}{l}-1.516 \\
(35.203)\end{array}$ \\
\hline $\operatorname{Age}^{2} / 10^{2}$ & $\begin{array}{c}-1.076 \\
(7.067)\end{array}$ & $\begin{array}{c}-1.926 \\
(7.177)\end{array}$ \\
\hline $\operatorname{Age}^{3} / 10^{3}$ & $\begin{array}{c}0.306 \\
(0.517)\end{array}$ & $\begin{array}{c}0.587 \\
(0.502)\end{array}$ \\
\hline $\operatorname{Age}^{4} / 10^{4}$ & $\begin{array}{c}-0.026^{* *} \\
(0.007)\end{array}$ & $\begin{array}{c}-0.045^{* *} \\
(0.003)\end{array}$ \\
\hline Duration dependence & & \\
\hline$\lambda_{30-90}$ & $\begin{array}{l}0.740^{* *} \\
(0.171)\end{array}$ & $\begin{array}{c}2.538^{* *} \\
(0.522)\end{array}$ \\
\hline$\lambda_{90-150}$ & $\begin{array}{l}1.085^{* *} \\
(0.182)\end{array}$ & $\begin{array}{c}3.653^{* *} \\
(0.519)\end{array}$ \\
\hline$\lambda_{150-210}$ & $\begin{array}{l}1.145^{* *} \\
(0.231)\end{array}$ & $\begin{array}{l}4.427^{* *} \\
(0.535)\end{array}$ \\
\hline$\lambda_{210-300}$ & $\begin{array}{c}0.829^{* *} \\
(0.283)\end{array}$ & $\begin{array}{c}5.632^{* *} \\
(0.553)\end{array}$ \\
\hline$\lambda_{300-390}$ & $\begin{array}{l}1.028^{* *} \\
(0.341)\end{array}$ & $\begin{array}{c}6.062^{* *} \\
(0.597)\end{array}$ \\
\hline$\lambda_{390-480}$ & $\begin{array}{l}1.431^{* *} \\
(0.368)\end{array}$ & $\begin{array}{l}4.965^{* *} \\
(1.041)\end{array}$ \\
\hline$\lambda_{480-656}$ & $\begin{array}{c}1.356^{* *} \\
(0.414)\end{array}$ & $\begin{array}{c}5.750^{* *} \\
(0.900)\end{array}$ \\
\hline Unobserved heterogeneity & & \\
\hline$v_{1}$ & $\begin{array}{l}-0.390 \\
(54.358)\end{array}$ & $\begin{array}{l}-1.663 \\
(57.672)\end{array}$ \\
\hline$v_{2}$ & $\begin{array}{l}-2.235 \\
(54.339)\end{array}$ & $\begin{array}{l}-6.089 \\
(57.639)\end{array}$ \\
\hline$p_{11}$ & $\begin{array}{c}0.473^{* *} \\
(0.111)\end{array}$ & \\
\hline$p_{21}$ & $\begin{array}{c}0.186^{*} \\
(0.106)\end{array}$ & \\
\hline$p_{12}$ & $\begin{array}{c}0.208^{* *} \\
(0.080)\end{array}$ & \\
\hline$p_{22}$ & $\begin{array}{c}0.134^{*} \\
(0.068)\end{array}$ & \\
\hline Loglikelihood & \multicolumn{2}{|c|}{-6973.03} \\
\hline Observations & \multicolumn{2}{|c|}{1144} \\
\hline
\end{tabular}

** indicates significance at the $1 \%$ level * significance at the $5 \%$ level. Standard errors given in parenthesis. 
Table 10: Treatment effects using regression discontinuity (unemployed workers between age 40 and 60$)$.

\begin{tabular}{|c|c|c|c|c|c|}
\hline & $(\mathrm{s}=3, \mathrm{t}=4)$ & $(\mathrm{s}=3, \mathrm{t}=6)$ & $(\mathrm{s}=0, \mathrm{t}=6)$ & $(\mathrm{s}=6, \mathrm{t}=\mathbf{9})$ & $(\mathrm{s}=6, \mathrm{t}=12)$ \\
\hline \multicolumn{6}{|c|}{ Continuous-time model } \\
\hline \multirow[t]{2}{*}{$Y_{0, s}^{*}$} & 0.179 & 0.179 & 0.000 & 0.381 & 0.381 \\
\hline & $(0.012)$ & $(0.012)$ & $(-)$ & $(0.015)$ & $(0.015)$ \\
\hline \multirow{2}{*}{$Y_{0, t}^{*}$} & 0.257 & 0.381 & 0.381 & 0.490 & 0.568 \\
\hline & $(0.012)$ & $(0.015)$ & $(0.015)$ & $(0.020)$ & $(0.026)$ \\
\hline \multirow[t]{2}{*}{$Y_{1, t}^{*}(s)$} & 0.220 & 0.294 & 0.233 & 0.443 & 0.494 \\
\hline & $(0.014)$ & $(0.023)$ & $(0.041)$ & $(0.015)$ & $(0.017)$ \\
\hline \multirow[t]{2}{*}{$\Delta(\mathbf{s}, \mathbf{t})$} & $-0.045^{* *}$ & $-0.105^{* *}$ & $-0.148^{* *}$ & $-0.075^{* *}$ & $-0.120^{* *}$ \\
\hline & $(0.013)$ & $(0.032)$ & $(0.046)$ & $(0.029)$ & $(0.046)$ \\
\hline \multicolumn{6}{|c|}{ Discrete-time model } \\
\hline \multirow[t]{2}{*}{$Y_{0, s}^{*}$} & 0.198 & 0.198 & 0.000 & 0.446 & 0.446 \\
\hline & $(0.013)$ & $(0.013)$ & $(-)$ & $(0.020)$ & $(0.020)$ \\
\hline \multirow[t]{2}{*}{$Y_{0, t}^{*}$} & 0.372 & 0.687 & 30.308 & 2.421 & 2.806 \\
\hline & $(0.276)$ & $(0.499)$ & $(28.410)$ & $(5.689)$ & $(5.821)$ \\
\hline \multirow[t]{2}{*}{$Y_{1, t}^{*}(s)$} & 0.224 & 0.268 & 0.333 & 0.467 & 0.582 \\
\hline & $(0.082)$ & $(0.138)$ & $(11.168)$ & $(2.048)$ & $(2.586)$ \\
\hline \multirow[t]{2}{*}{$\Delta(\mathbf{s}, \mathbf{t})$} & -0.184 & -0.523 & -29.975 & -3.526 & -4.012 \\
\hline & $(0.285)$ & $(0.515)$ & $(28.750)$ & $(5.811)$ & $(6.103)$ \\
\hline
\end{tabular}

** indicates significance at the $1 \%$ level, * significance at the $5 \%$ level.

We estimate the matching and Logit functions with the same covariates as in the timing of events model.

\subsection{Treatment Effects using Regression-Discontinuity Meth- ods}

When estimating both regression-discontinuity models specified above we consider only individuals between age 40 and 60 at the moment of becoming unemployed. Furthermore, we exclude all low-skilled workers from the analyses. Table 9 shows the parameter estimates for the continuous-time regression-discontinuity model. The effect of participating in the job search assistance program is again negative and significant. Individuals age 50 and older are indeed more likely to enter job search assistance. Also, the exit rate from unemployment is slightly higher for individuals just above age 50 compared to individuals just below age 50 , but this ex-ante effect of the program is not significant. We find some dispersion in unobserved heterogeneity in both hazard rates. The correlation between the unobserved heterogeneity terms is 0.11 and very insignificant.

As in the timing-of-events model, we can translate the estimated hazards into the treatment effects $\Delta(s, t)$. These are shown in the upper panel of Table 10 . The estimated treatment effects are negative and significant. In the bottom panel of the table, we show the same treatment effects estimated using the discrete-time regression-discontinuity model. As previously in the baseline propensity score model, we take the unit of time $(\tau)$ equal to 30 days. For the treatment effect of entering job 
search assistance after three months $(s=3)$ we find large negative effects, but also very large standard errors. This is mainly because estimating the potential untreated outcomes is problematic. When estimating the treatment effect for entering in the first month $(s=0)$ we again experience the problem of only having a treated

few observations. For entering job search assistance after six months $(s=6)$, the estimated treatment effects do not make sense, i.e. the probabilities are outside the zero to one interval. The main reason is that after six months of unemployment all individuals should enter the job search assistance program. This implies that our instrumental variable $50^{+}$loses power when evaluating job search assistance beyond six months of unemployment. The results in the final two columns are thus the consequence of a weak instruments problem.

\section{Comparing the different methods}

In the previous sections we provided results for the different estimation methods. In this section we briefly compare these results. We ignore the results from the discrete-time regression discontinuity model, because these results suffered from too few observations, and, therefore, estimation results were very imprecise. In Table 11 we summarize the effects of participating in the job search assistance program obtained using the different methods. All methods show negative treatment effects for all cases.

The results of the baseline timing-of-events model are relatively close to the results from the continuous-time regression-discontinuity model. This is not very surprising since both models estimate a permanent homogeneous treatment effect. However, the subsamples used in the estimation differ between both analyses. In the timing-of-events model we considered the full sample, while in the regressiondiscontinuity analysis we focused only on unemployed workers between age 40 and 60. The results of the timing-of-events model change somewhat when we allow the treatment effect to depend on the elapsed unemployment duration when entering the job search assistance program. The treatment effect becomes more negative for entry after three months of unemployment and less negative for entry in the program after six months of unemployment.

The treatment effects obtained from propensity score matching are less precise than the results from the continuous-time duration models. This is mainly caused by the substantial reduction in the sample size due to constructing a matched control group. Recall that for the matched control group we had to estimate exit probabilities conditional on observables to deal with later entry in the program. We estimated the exit rates using logit models which, due to small sample sizes, pro- 
Table 11: Comparison of results.

\begin{tabular}{|c|c|c|c|c|c|}
\hline & $(\mathrm{s}=3, \mathrm{t}=4)$ & $(\mathrm{s}=3, \mathrm{t}=6)$ & $(\mathbf{s}=\mathbf{0}, \mathbf{t}=\mathbf{6})$ & $(\mathrm{s}=6, \mathrm{t}=\mathbf{9})$ & $(\mathrm{s}=6, \mathrm{t}=12)$ \\
\hline \multicolumn{6}{|c|}{ Timing of events: baseline model } \\
\hline \multirow[t]{2}{*}{$Y_{0, s}^{*}$} & 0.301 & 0.301 & 0.000 & 0.521 & 0.521 \\
\hline & $(0.008)$ & $(0.008)$ & $(-)$ & $(0.008)$ & $(0.008)$ \\
\hline \multirow{2}{*}{$Y_{0, t}^{*}$} & 0.388 & 0.521 & 0.521 & 0.637 & 0.716 \\
\hline & $(0.007)$ & $(0.008)$ & $(0.008)$ & $(0.009)$ & $(0.010)$ \\
\hline \multirow[t]{2}{*}{$Y_{1, t}^{*}(s)$} & 0.362 & 0.465 & 0.414 & 0.606 & 0.670 \\
\hline & $(0.009)$ & $(0.013)$ & $(0.024)$ & $(0.009)$ & $(0.010)$ \\
\hline \multirow[t]{2}{*}{$\Delta(\mathbf{s}, \mathbf{t})$} & $-0.037^{* *}$ & $-0.081^{* *}$ & $-0.108^{* *}$ & $-0.066^{* *}$ & $-0.096^{* *}$ \\
\hline & $(0.008)$ & $(0.018)$ & $(0.025)$ & $(0.015)$ & $(0.022)$ \\
\hline \multicolumn{6}{|c|}{ Timing of events: effect dependent on unemployment duration at entering } \\
\hline \multirow[t]{2}{*}{$Y_{0, s}^{*}$} & 0.302 & 0.302 & 0.000 & 0.523 & 0.523 \\
\hline & $(0.008)$ & $(0.008)$ & $(-)$ & $(0.008)$ & $(0.008)$ \\
\hline \multirow{2}{*}{$Y_{0, t}^{*}$} & 0.389 & 0.523 & 0.523 & 0.640 & 0.716 \\
\hline & $(0.007)$ & $(0.008)$ & $(0.008)$ & $(0.009)$ & $(0.011)$ \\
\hline \multirow[t]{2}{*}{$Y_{1, t}^{*}(s)$} & 0.348 & 0.431 & 0.341 & 0.618 & 0.685 \\
\hline & $(0.009)$ & $(0.016)$ & $(0.033)$ & $(0.010)$ & $(0.012)$ \\
\hline \multirow[t]{2}{*}{$\Delta(\mathbf{s}, \mathbf{t})$} & $-0.058^{* *}$ & $-0.132^{* *}$ & $-0.183^{* *}$ & $-0.046^{*}$ & $-0.065^{*}$ \\
\hline & $(0.009)$ & $(0.023)$ & $(0.034)$ & $(0.019)$ & $(0.027)$ \\
\hline \multicolumn{6}{|c|}{ Propensity score matching } \\
\hline \multirow[t]{2}{*}{$Y_{0, s}^{*}$} & 0.307 & 0.307 & 0.000 & 0.563 & 0.563 \\
\hline & $(0.011)$ & $(0.011)$ & $(-)$ & $(0.014)$ & $(0.014)$ \\
\hline \multirow{2}{*}{$Y_{0, t}^{*}$} & 0.360 & 0.393 & 0.384 & 0.668 & 0.710 \\
\hline & $(0.041)$ & $(0.080)$ & $(0.315)$ & $(0.079)$ & $(0.121)$ \\
\hline \multirow{2}{*}{$Y_{1, t}^{*}(s)$} & 0.322 & 0.348 & 0.222 & 0.620 & 0.702 \\
\hline & $(0.013)$ & $(0.024)$ & $(0.155)$ & $(0.037)$ & $(0.051)$ \\
\hline \multirow[t]{2}{*}{$\Delta(\mathbf{s}, \mathbf{t})$} & -0.054 & -0.065 & -0.162 & -0.110 & -0.019 \\
\hline & $(0.043)$ & $(0.084)$ & $(0.350)$ & $(0.089)$ & $(0.132)$ \\
\hline \multicolumn{6}{|c|}{ Continuous-time regression-discontinuity } \\
\hline \multirow[t]{2}{*}{$Y_{0, s}^{*}$} & 0.179 & 0.179 & 0.000 & 0.381 & 0.381 \\
\hline & $(0.012)$ & $(0.012)$ & $(-)$ & $(0.015)$ & $(0.015)$ \\
\hline \multirow[t]{2}{*}{$Y_{0, t}^{*}$} & 0.257 & 0.381 & 0.381 & 0.490 & 0.568 \\
\hline & $(0.012)$ & $(0.015)$ & $(0.015)$ & $(0.020)$ & $(0.026)$ \\
\hline \multirow[t]{2}{*}{$Y_{1, t}^{*}(s)$} & 0.220 & 0.294 & 0.233 & 0.443 & 0.494 \\
\hline & $(0.014)$ & $(0.023)$ & $(0.041)$ & $(0.015)$ & $(0.017)$ \\
\hline \multirow[t]{2}{*}{$\Delta(\mathbf{s}, \mathbf{t})$} & $-0.045^{* *}$ & $-0.105^{* *}$ & $-0.148^{* *}$ & $-0.075^{* *}$ & $-0.120^{* *}$ \\
\hline & $(0.013)$ & $(0.032)$ & $(0.046)$ & $(0.029)$ & $(0.046)$ \\
\hline
\end{tabular}

** indicates significance at the $1 \%$ level, ${ }^{*}$ significance at the $5 \%$ level 
duce quite substantial standard errors. The treatment effects from propensity score matching are, therefore, never significant. But the estimated treatment effects are also somewhat different for the propensity score method than for the other methods. The difference between methods is not as large as found by Lalive, van Ours and Zweimüller (2008). However, in their case it is not clear that the conditional independence assumption is satisfied, and violation of this assumption might be an explanation for the difference in estimated treatment effect.

Finally, it is interesting to consider entry in the job search assistance program during the first month $(s=0)$. In this case, there is not yet any dynamic selection and differences between methods are thus largely the effect of different functionalform assumptions. For this case again the propensity score methods provides insignificant effects of participating in the treatment, but the parameter estimate is relatively close to the timing-of-events methods where we allow the treatment effect to depend on the elapsed unemployment duration when entering the job search program.

\section{Conclusions}

In this paper we used different methods to evaluate the effectiveness of a job search assistance program for unemployed workers within a dynamic setting. The data come from a unique institutional setting, which allows for the use of different methods. In particular, we used timing-of-events, propensity score matching and regression-discontinuity methods. All methods indicate negative (and often significant) ex-post effects of participating in job search assistance on the exit from unemployment.

As stated by Abbring and Van den Berg (2003), the identification of a treatment effect within the timing-of-events model hinges on the no-anticipation assumption and imposes mixed proportional hazard rates. We argue that exploiting a policy discontinuity or the usual conditional independence assumption cannot replace the no-anticipation assumption. It is important to stress that whereas papers using the timing-of-events approach justify the no-anticipation assumption extensively, this is almost always ignored in papers using other approaches to evaluate dynamic treatment effects.

The conditional independence assumption can only be used to relax the mixed proportional hazard rate structure of the timing-of-events model. However, when applying propensity score matching methods it is necessary to discretize time to deal with continuous inflow into the program. In the empirical analyses we have shown that our results are not very robust against the choice of the unit of time. 
Furthermore, taking account of later entry in the job search assistance program in the control group requires a more formal model for exit from unemployment in the control group. When actually taking account of this type of right-censoring, the estimators for the treatment effect become much less precise.

Exploiting the regression-discontinuity design within our setting is complicated. Within the timing-of-events model the policy discontinuity only identifies possible ex-ante effects of the program which can not be exploited to estimate the effect of actually participating in the program. This also explains why the estimated treatment effects in this model are close to those in the baseline timing-of-events model. Relaxing the parametric structure is problematic. First, to estimate dynamic treatment effects using a regression discontinuity requires the absence of ex-ante effects, which is a stronger requirement than assuming no-anticipation. Furthermore, to deal with dynamic selection a conditional independence assumption is also required.

Recall that in our application we focus on individuals in the primary education sector collecting unemployment insurance benefits. Unemployed workers from the primary school sector differ from other unemployed workers, for example, in composition and where they search for new employment. For this group of unemployed workers we find that participating in the job search assistance program does not stimulate exit from unemployment. The job search assistance program is a general program provided by commercial training agencies and many unemployed workers in the private sector also participate in this program. Our results are only informative on how this job search assistance program affects the exit rate from unemployment of unemployed workers in the primary school sector. The poor performance might be the consequence of a mismatch between the program and this group of unemployed workers rather than the program being ineffective in general. For example, the program might press participants to search for work in the general labor market, while unemployed workers in the primary education sector mainly search for teaching jobs at primary schools.

As a consequence of the results discussed in this paper, the job search assistance program has been modified in a number of ways. First, after two months of unemployment there is now an introductory meeting in which individuals are informed about the program. The Participation Fund indicates that this reduces the resistance to participate in the program. In the new setup, individuals only enter the program after having collected benefits for eight months. This is later than in the previous setup and there is no difference anymore for individuals below and above age 50. The previous results indicate that the program effect is less negative if entry is later during the unemployment spell and expenditures also decreased because less individuals actually enter the program. Finally, the job search assistance program now has some voluntary elements, so individuals have some discretion to choose 
their degree of assistance. 


\section{References}

Abbring, J.H. and J.J. Heckman (2007), "Econometric evaluation of social programs, part III: Distributional treatment effects, dynamic treatment effects and dynamic discrete choice, and general equilibrium policy evaluation", Chapter 72 in J.J. Heckman and E. Leamer, editors, Handbook of Econometrics, Volume 6B, 51455303, Elsevier Science, Amsterdam.

Abbring, J., and G.J. van den Berg, (2003), "The nonparametric identification of treatment effects in duration models", Econometrica 71(5): 1491-1517.

Abbring, J.H. and G.J. van den Berg (2005), "Social experiments and instrumental variables with duration outcomes", Tinbergen Institute Discussion Paper 2005$047 / 3$.

Bonnal, L., D. Fougère and A. Serandon (1997), "Evaluating the impact of French employment policies on individual labour market histories", Review of Economic Studies 64(4): 683-713.

Black, D., J. Smith, M. Berger and B. Noel (2003), "Is the threat of reemployment services more effective than the services themselves? Evidence from random assignment in the UI system", American Economic Review 93(4): 1313-1327.

Card, D., J. Kluve and A. Weber (2010), "Active labour market policy evaluations: a meta-analysis", Economic Journal 120: F452-477.

Crépon, B., M. Ferracci, G. Jolivet and G.J. van den Berg (2010), "Analyzing the Anticipation of Treatments Using Data on Notification Dates", Discussion Paper 5265, IZA Bonn.

Fredriksson, P. and P. Johansson (2008), "Dynamic treatment assignment: the consequences for evaluations using observational data", Journal of Business and Economic and Statistics 26(4): 435-445.

Gerfin M. and M. Lechner (2002), "A microeconometric evaluation of the active labour market policy in Switzerland", Economic Journal 112: 854-893.

Hahn, J., P. Todd and W. van der Klaauw (2001), "Identification and estimation of treatment effects with a regression-discontinuity design", Econometrica 69(1): 201-209.

Imbens, G.W. and D.B. Rubin (1997), "Estimating outcome distributions for compliers in instrumental variables models", Review of Economic Studies 64(4): 555574 .

Imbens, G.W. and J.M. Wooldridge (2009), "Recent developments in the econometrics of program evaluation", Journal of Economic Literature 47(1): 5-86. 
Lalive, R., J.C. van Ours and J. Zweimller (2008), "The impact of active labour market programmes on the duration of unemployment in Switzerland", Economic Journal 118: 235-257.

Lechner, M. (1999) "Earnings and employment effects of continuous off-the-Job training in East-Germany after unification", Journal of Business and Economic Statistics 17(1): 74-90.

Lechner, M. (2009), "Sequential causal models for the evaluation of labor market programs", Journal of Business and Economic Statistics 27(1): 71-83.

Lechner, M. and C. Wunsch (2009), "Are training programs more effective when unemployment is high?", Journal of Labor Economics 27(4): 653-692.

OECD (2010), "Employment Outlook", OECD, Paris.

Ridder, G. (1984), "The distribution of single-spell duration data", in G.R. Neumann and N. Westergård-Nielsen (eds.), Studies in Labor Market Analysis, SpringerVerlag, Berlin.

Rosenzweig, M.R. and K.I. Wolpin (2000), "Natural "natural experiments" in economics", Journal of Economic Literature 38(4): 827-874.

Sianesi, B. (2004), "An evaluation of the Swedish system of active labor market programs in the 1990's", Review of Economics and Statistics 86(1): 133-155.

Van den Berg, G.J. and B. van der Klaauw (2006), "Counseling and monitoring of unemployed workers: theory and evidence from a controlled randomized experiment", International Economic Review 47(3): 895-936.

Van den Berg, G.J., B. van der Klaauw and J.C. van Ours (2004), "Punitive sanctions and the transition from welfare to work", Journal of Labor Economics 22(1): 211-241. 